\title{
Crystal Structure, Raman Spectroscopy and Dielectric Properties of New Semiorganic Crystals Based on 2-Methylbenzimidazole
}

\author{
E. V. Balashova ${ }^{1, *(1)}$, F. B. Svinarev ${ }^{1}$, A. A. Zolotarev ${ }^{2}$, A. A. Levin ${ }^{1}$, P. N. Brunkov ${ }^{1}$, \\ V. Yu. Davydov ${ }^{1}\left(\mathbb{D}\right.$, A. N. Smirnov $^{1}\left(\mathbb{D}\right.$, A. V. Redkov $^{3}$, G. A. Pankova $^{4}$ and B. B. Krichevtsov ${ }^{1}(\mathbb{D}$ \\ 1 Ioffe Institute, 26 Politekhnicheskaya, St Petersburg 194021, Russian Federation; \\ svinarev@mail.ioffe.ru (F.B.S.); aleksandr.a.levin@mail.ioffe.ru (A.A.L.); Brunkov@mail.ioffe.ru (P.N.B.); \\ Valery.Davydov@mail.ioffe.ru (V.Y.D.); Alex.Smirnov@mail.ioffe.ru (A.N.S.); boris@mail.ioffe.ru (B.B.K.) \\ Institute of Earth Sciences, Saint-Petersburg State University, 7/9 Universitetskaya Nab., St Petersburg \\ 199034, Russian Federation; a.zolotarev@spbu.ru \\ 3 Institute of Problems of Mechanical Engineering, 61 Bolshoy pr. V.O., St Petersburg 199004, Russian \\ Federation; red-alex@mail.ru \\ 4 Institute of macromolecular compounds, 31 Bolshoy pr. V.O., St Petersburg 199004, Russian Federation; \\ pankova@bk.ru \\ * Correspondence: balashova@mail.ioffe.ru
}

Received: 27 September 2019; Accepted: 29 October 2019; Published: 31 October 2019

\begin{abstract}
New single crystals, based on 2-methylbenzimidazole (MBI), of MBI-phosphite $\left(\mathrm{C}_{16} \mathrm{H}_{24} \mathrm{~N}_{4} \mathrm{O}_{7} \mathrm{P}_{2}\right)$, MBI-phosphate- $1\left(\mathrm{C}_{16} \mathrm{H}_{24} \mathrm{~N}_{4} \mathrm{O}_{9} \mathrm{P}_{2}\right)$, and MBI-phosphate-2 $\left(\mathrm{C}_{8} \mathrm{H}_{16} \mathrm{~N}_{2} \mathrm{O}_{9} \mathrm{P}_{2}\right)$ were obtained by slow evaporation method from a mixture of alcohol solution of MBI crystals and water solution of phosphorous or phosphoric acids. Crystal structures and chemical compositions were determined by single crystal X-ray diffraction (XRD) analysis and confirmed by XRD of powders and elemental analysis. Raman spectroscopy of new crystals evidences the presence in crystals of MBI-, $\mathrm{H}_{3} \mathrm{PO}_{3}$-, or $\mathrm{H}_{3} \mathrm{PO}_{4}$ - and water molecules. Dielectric properties of crystals reveal strong increase and low frequency dispersion of dielectric constant and losses at heating, indicating the appearance of proton conductivity. At low temperatures in MBI-phosphate-2, an increase of dielectric constant analogous to quantum paraelectric state is observed.
\end{abstract}

Keywords: semiorganic crystals; hydrogen bonds; crystal structure; XRD; crystal growth; Raman spectroscopy; dielectric properties; proton conductivity

\section{Introduction}

The search for and study of new organic and semiorganic materials possessing ferroelectric, ferroelastic, antiferroelectric, or piezoelectric properties is at present a subject of intensive research [1-3]. The interest in such substances is caused, in particular, by the need to obtain ecological, flexible, and low-cost functional materials for electronics, sensors for different fields, piezoelements, nonlinear optical devices [4,5], membranes for fuel cells for hydrogen energetics [6], biomedical and biotechnological devises, [7] etc.

The mechanisms responsible for the appearance of spontaneous polarization, piezoelectricity, and phase transformations in organic and semiorganic materials are also of fundamental interest. This is caused by specific features of organic molecules possessing an effect of tautomerism [8], and specific crystal structure, which often contains the chains of hydrogen bonds giving rise to polarization due to freezing of protons, or permits manifestation of charge transfer-induced polarization [9]. It is worth 
noting that organic and semiorganic crystals reveal a wide spectrum of phases including ferroelectric, antiferroelectric, ferroelastic phase [1,10-13], and quantum paraelectric states [14-16].

The last time, a number of organic and semiorganic ferroelectrics (croconic acid [12], diisopropylammonium iodide [17], etc.) were discovered, which revealed a high value of spontaneous polarization $P_{S}$ up to $\sim 20-30 \mu \mathrm{C} / \mathrm{cm}^{2}$ at room temperature, comparable with that in $\mathrm{PbZr}_{x} \mathrm{Ti}_{1-\mathrm{x}} \mathrm{O}_{3}$ (PZT), $\mathrm{Pb}_{1-y} \mathrm{La}_{\mathrm{y}} \mathrm{Zr}_{1-\mathrm{x}} \mathrm{Ti}_{\mathrm{x}} \mathrm{O}_{3}$ (PLZT). Organic single component ferroelectric 2-methylbenzimidazole (MBI), which crystalizes in a pseudo-tetragonal structure, has a smaller value of the spontaneous polarization $P_{S} \sim 5 \mu \mathrm{C} / \mathrm{cm}^{2}$ [18]. Nevertheless, in this crystal the polarization components may appear in two orthogonal directions along chains of hydrogen bonds between nitrogen ions, and the coercive field is relatively small $E_{c} \sim 2 \mathrm{kV} / \mathrm{cm}$, which makes this substance attractable for applications.

Recently, [19] new crystals based on a combination of MBI or imidazole with organic molecules (bridged bis(benzimidazole)s) have been grown and studied for getting thermally robust and highly polarizable dielectric substances due to multistability of their polar supramolecular architectures. Some of these crystals have noncentrosymmetric structure, and reveal increased thermostability and antiferroelectric double hysteresis loops.

It is well known that crystals formed by a combination of organic and inorganic acids may possess ferroelectricity. An example of this is a family of amino-acid ferroelectrics which are compositions of amino-acids (glycine, betaine, sarcosine, etc.) and inorganic (phosphorous, phosphoric, etc.) acids or salts $[11,20,21]$. Ferroelectric or antiferroelectric properties of such substances (betaine phosphate, betaine phosphite, betaine arsenate, glycine phosphite, etc.) are related mainly to freezing of protons in hydrogen bonds forming the zig-zag chains [11]. The value of polarization is about $3 \mu \mathrm{C} / \mathrm{cm}^{2}$ and Curie temperature may be above room temperature in deuterated crystals [22,23].

Because the cyclic molecules, such as imidazole or amino acid molecules, containing the imidazole ring (for example, histidine), can form with inorganic acids the crystals with noncentrosymmetric structure [24,25], it looks interesting to see which new crystals can be synthesized using a combination of organic MBI and inorganic acids, and also study their structural and dielectric properties. In this paper we present the results of a study of three new crystals grown from a solution of 2-methylbenzimidazole and phosphorous $\mathrm{H}_{3} \mathrm{PO}_{3}$ or phosphoric $\mathrm{H}_{3} \mathrm{PO}_{4}$ acids. X-ray diffraction (XRD) studies of crystal structures are confirmed by analysis of Raman spectra of new crystals. Dielectric measurements are also presented.

\section{Materials and Methods}

The crystals of MBI-phosphite $\left(\mathrm{C}_{16} \mathrm{H}_{24} \mathrm{~N}_{4} \mathrm{O}_{7} \mathrm{P}_{2}\right)$ were grown by slow evaporation method from a mixture of alcohol solution of MBI single crystals and water solution of phosphorous acid. The molar proportion of MBI and $\mathrm{H}_{3} \mathrm{PO}_{3}$ components in the mixture was 1:1. The crystals were recrystallized several times from a solution in deionized water.

Chemical formula of MBI-phosphate- $1\left(\mathrm{C}_{16} \mathrm{H}_{24} \mathrm{~N}_{4} \mathrm{O}_{9} \mathrm{P}_{2}\right)$ and MBI-phosphate-2 $\left(\mathrm{C}_{8} \mathrm{H}_{16} \mathrm{~N}_{2} \mathrm{O}_{9} \mathrm{P}_{2}\right)$ crystals is characterized by $1: 1$ and 1:2 molar proportions of $\mathrm{MBI}$ and $\mathrm{H}_{3} \mathrm{PO}_{4}$ components, correspondingly. These crystals were grown by slow evaporation method from a mixture of saturated alcohol solution of MBI single crystals and $75 \%$ water solution of phosphoric acid. The molar proportion of the MBI and the acid in the mixture was 1:1 and 1:2. MBI crystals used in these processes were obtained by recrystallization of commercial MBI powder in alcohol solution with adding the activated carbon. Figure 1 shows the photos of synthesized crystals. Images obtained in a polarizing microscope indicate that the crystals are homogeneous without blocks and intergrowths. 

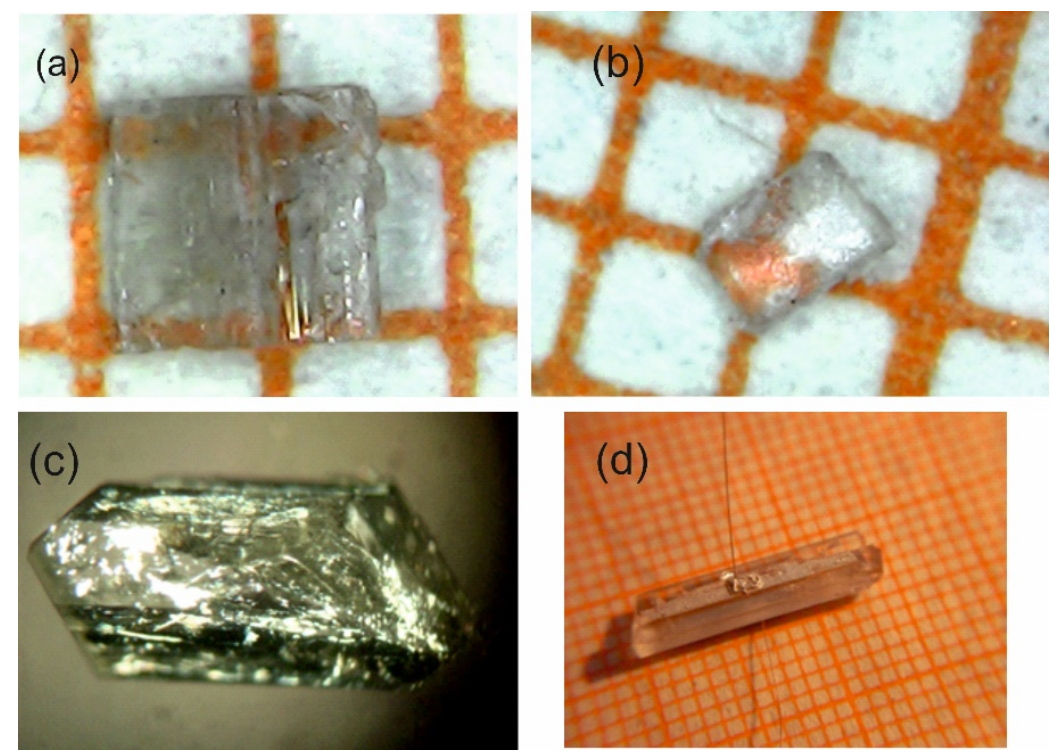

Figure 1. Photos of crystals of MBI-phosphite (a,b), MBI-phosphate-1 (c), MBI-phosphate-2 (d). The grid step in Figure $1(\mathbf{a}, \mathbf{b}, \mathbf{d})$ is $1 \mathrm{~mm}$. Crystal length on Figure 1 (c) is several millimeters.

For a single crystal XRD experiment, suitable crystals were fixed on a micro mount and placed on a Bruker Kappa APEX DUO diffractometer (Bruker AXS, Madison, WI, USA) and were measured at a room temperature using monochromated Mo-K $\alpha$ radiation. The structures were solved by the direct methods by means of the SHELX program [26] incorporated in the OLEX2 program package [27]. The intensity data were reduced and corrected for Lorentz, polarization, and background effects using the Bruker software APEX2 (Version 2014.11-0, Bruker-AXS, Madison, WI, USA) [28]. A semiempirical absorption-correction based upon the intensities of equivalent reflections was applied using SADABS (Version 2007, Bruker-AXS, Madison, WI, USA) [29]. The crystallographic data and some parameters of refinement are placed in the Table 1 . The carbon and nitrogen-bound $\mathrm{H}$ atoms were placed in calculated positions and included in the refinement in the 'riding' model approximation, with $\mathrm{U}_{\text {iso }}(\mathrm{H})$ set to $1.2 \mathrm{U}_{\text {eq }}(\mathrm{C})$ and $\mathrm{C}-\mathrm{H} 0.93 \AA$ for the $\mathrm{CH}$ groups, with $\mathrm{U}_{\text {iso }}(\mathrm{H})$ set to $1.5 \mathrm{U}_{\text {eq }}(\mathrm{C})$ and $\mathrm{C}-\mathrm{H} 0.96 \AA$ for the $\mathrm{CH}_{3}$ groups, and with $\mathrm{U}_{\text {iso }}(\mathrm{H})$ set to $1.2 \mathrm{U}_{\mathrm{eq}}(\mathrm{N})$ and $\mathrm{N}-\mathrm{H} 0.86 \AA$ for the $\mathrm{NH}$ groups. All $\mathrm{H}$ atoms bonded to $\mathrm{O}$ atoms were located in the difference Fourier map and refined in an isotropic approximation and were fixed using DFIX instruction. The $\mathrm{H}$ atoms of $\mathrm{HPO}_{3}$ groups were localized from difference Fourier maps as well. Crystal structures were drawn by means of program VESTA [30].

MBI-phosphite and MBI-phosphate-1 were investigated by means of powder XRD as well. XRD measurement of MBI-phosphite powder was carried out on the powder X-ray diffractometer D2 PHASER (Bruker AXS, Germany) in the vertical Bragg-Brentano geometry. Cu- $K \alpha$ radiation $(\lambda=1.540598 \AA)$ monochromatized by Ni filter was used. The XRD powder patterns were measured using the position-sensitive semiconductor linear X-ray detector LYNXEYE.

Due to a small amount of the material necessary for investigations by other techniques, MBI-phosphate-1 was not milled and was utilized for XRD powder measurements as is. The powder of MBI-phosphite was thoroughly ground in a corundum mortar to reduce the possible effects of the preferred orientation of the crystallites. The MBI-phosphite powder without milling was measured for comparison as well.

The prepared powder was poured onto the glass substrate without the use of any fluids to avoid dissolution. To reduce the effects of the preferred orientation of the crystallites during the measurements, the powder sample was rotated around the goniometer axis perpendicular to the substrate. The correction shifts $\left(\Delta 2 \theta_{\text {zero }}\right)$ of the XRD patterns were applied utilizing the results of the additional measurements of the sample powders in the mixture with certified standard silicon powder Si640d (NIST, USA). All measurements were performed at room temperature. 
The model XRD patterns were simulated and fitted to the experimental ones by means of the Rietveld program TOPAS [31]. For the reflection profile fitting, a modified Thompson-Cox-Hastings pseudo-Voigt (TCHZ) model $[32,33]$ was used. For description of the emission spectrum of the $\mathrm{Cu}-\mathrm{K} \alpha$ radiation, the Berger model of the five spectral lines [34] was utilized.

As primary data for Rietveld refinement [35] of the structure, the atomic coordinates determined in corresponding single crystal investigations (Tables S1, S11 of Supplementary Materials (SM)) were used. Conventional weight scheme $w_{i}=1 / I_{i}\left(I_{i}\right.$ is the intensity value at diffraction angle $2 \theta_{i}$ of the $i$-th step of the XRD pattern) was utilized for the refinement. The start values of unit cell parameters for the Rietveld refinement were obtained by means of Le Bail whole powder pattern fitting [36] the simulated XRD pattern to the experimental one. During the refinement, the overall isotropic temperature factors $U_{\text {iso }}$ overall were refined for every sort of atom. The XRD patterns, especially in the case of MBI-phosphate-1, which was not milled, were influenced by the effect of preferred orientation of crystallites, resulting in enhanced intensities of some reflections and decreased intensities of others. The main contribution of the preferred orientation effect was corrected in frames of the March-Dollase approach [33,37] using two directions of the preferred orientation ([101] and [102] for MBI-phosphate-1 and [110] and [100] for MBI-phosphite) as it is implemented in TOPAS. The remaining contribution of other directions of preferred orientation was corrected using a model of spherical harmonics of eighth order [38]. Strong influence of the preferred orientation on the XRD pattern of MBI-phosphate-1 resulted in difficulties in obtaining the reliable interatomic distances after refinement of the atomic coordinates. Therefore, the atomic coordinates of the MBI-phosphate- 1 determined by means of single crystal investigation were not refined from the XRD powder data. Grinding of the powder in the case of MBI-phosphite greatly reduced the effect of the preferential orientation. In the subsequent stages, the coordinates of nonhydrogen atoms were refined, following the reliability of interatomic distances. The coordinates of the hydrogen atoms were recalculated from those determined on the single crystal investigation, taking into account the refined parameters of the unit cell. At the final stage, they were refined by imposing restrictions on the values of the $\mathrm{M}-\mathrm{H}$ distances in the nearest coordination sphere of the $\mathrm{M}$ atoms $(\mathrm{M}=\mathrm{P}, \mathrm{O}, \mathrm{N}, \mathrm{C})$, assuming that these distances cannot deviate from the average values obtained from single crystal data by more than $0.1 \AA$. Further details $[39,40]$ of the experiment and refinement procedure are thoroughly described in SM.

The elemental composition of the crystals was analyzed by energy dispersive X-ray spectroscopy (EDX) using electron microprobe analysis exploring an EVA-40 microscope (Carl Zeiss Jena) and INCA (Oxford Instruments), an energy dispersive detector. The energy of the electron beam was $12 \mathrm{keV}$. The energy resolution of the detector was $200 \mathrm{eV}$, and it can identify elements from $\mathrm{Be}$ to $\mathrm{Pu}$.

Raman spectroscopy measurements were carried out on both powders and single crystals. Raman spectra of MBI, MBI-phosphate-1, and MBI-phosphate-2 single crystals were obtained in the spectral region $80-3300 \mathrm{~cm}^{-1}$ by means of Alpha 300R confocal microscope (Witec, Germany) in geometry of backscattering with the use of a laser diode operating at $\lambda=532 \mathrm{~nm}$. Incident light was linearly polarized along or perpendicular to the longest of the edges of the crystal. No polarizer was there on the way of scattered light.

Polarized Raman spectra of the MBI-phosphite on both powders and single crystals were measured with use of T64000 Advanced Research Raman System (Horiba Jobin-Yvon, France). Measurements were carried out in the spectral interval $5-4000 \mathrm{~cm}^{-1}$ in backscattering for different experimental geometries $-Z(X X) Z,-Z(Y Y) Z$, and $-Z(X Y) Z$, where $Z$-axis is oriented normally to the crystal surface (100), and $X$ and $Y$ are along $c^{*}$ - and $b$-crystal axes, respectively.

Measurements of capacity and dielectric losses were performed in the frequency range $25-10^{6} \mathrm{~Hz}$ and temperature interval 8-380 K with LCR meter E4980A (Agilent Technologies, USA), LCR-meters MIT 9216A (Protek, USA), and E7-20 (MNIPI, Belarus), using the LabView software package (Version 2011, NIST, USA). Silver glue was used for preparing the electrodes on the natural faces of the crystals. Temperature dependence of conductivity was calculated from dielectric data. 


\section{Results and Discussion}

\subsection{Single Crystal XRD}

Crystal data and structure refinement details of obtained crystals are summarized in Table 1. Crystallographic information files (CIFs) were deposited at Cambridge Crystallographic Data Centre (1949405-1949407) and can be obtained free of charge via www.ccdc.cam.ac.uk/data_request/cif. Coordinates of atoms and their equivalent isotropic/isotropic temperature factors $\mathrm{U}_{\mathrm{eq}} / \mathrm{U}_{\mathrm{iso}}$, atomic displacemence parameters, bond lengths, bond angles, and geometry of hydrogen bonds according to the results of the single crystal refinements are presented in Tables S1-S15 of the SM. (See Supplementary Materials)

Table 1. Details of crystal data and structure refinement of single crystals.

\begin{tabular}{|c|c|c|c|}
\hline & MBI-Phosphite & MBI-Phosphate-1 & MBI-Phosphate-2 \\
\hline Chemical Formula & $\mathrm{C}_{16} \mathrm{H}_{24} \mathrm{~N}_{4} \mathrm{O}_{7} \mathrm{P}_{2}$ & $\mathrm{C}_{16} \mathrm{H}_{24} \mathrm{~N}_{4} \mathrm{O}_{9} \mathrm{P}_{2}$ & $\mathrm{C}_{8} \mathrm{H}_{16} \mathrm{~N}_{2} \mathrm{O}_{9} \mathrm{P}_{2}$ \\
\hline Temperature, K & 293 & 293 & 296 \\
\hline Formula Weight & 446.33 & 478.33 & 345.16 \\
\hline Crystal System & Monoclinic & Triclinic & Triclinic \\
\hline Space Group & $P 2_{1} / c(N 14)$ & $P \overline{1}(N)$ & $P \overline{1}(N 2)$ \\
\hline$a, \AA$ & $17.1966(6)$ & $9.574(9)$ & $6.8476(3)$ \\
\hline$b, \AA$ & $17.7098(7)$ & $9.779(9)$ & $10.1778(4)$ \\
\hline$c, \AA$ & $6.9992(4)$ & $11.796(10)$ & $11.0834(5)$ \\
\hline$\alpha,{ }^{\circ}$ & 90 & $88.294(18)$ & $87.953(1)$ \\
\hline$\beta,^{\circ}$ & 94.963(4) & $78.07(2)$ & $85.546(1)$ \\
\hline$\gamma_{1}^{\circ}$ & 90 & $87.646(19)$ & $74.760(1)$ \\
\hline$V, \AA^{3}$ & $2123.60(17)$ & 1079.3(17) & $742.93(6)$ \\
\hline Z & 4 & 2 & 2 \\
\hline$D_{\text {calc }}, \mathrm{g} \mathrm{cm}^{-3}$ & 1.396 & 1.472 & 1.548 \\
\hline$F(000)$ & 936.0 & 500.0 & 358.0 \\
\hline$\mu, \mathrm{mm}^{-1}$ & 0.250 & 0.258 & 0.337 \\
\hline Crystal Size, $\mathrm{mm}^{3}$ & $0.22 \times 0.18 \times 0.12$ & $0.25 \times 0.14 \times 0.10$ & $0.22 \times 0.16 \times 0.11$ \\
\hline Radiation & Mo- $K_{\alpha}(\lambda=0.71073 \AA)$ & Mo- $K_{\alpha}(\lambda=0.71073 \AA)$ & Mo- $K_{\alpha}(\lambda=0.71073 \AA)$ \\
\hline $\begin{array}{c}2 \theta \text { Range for Data } \\
\text { Collection }\end{array}$ & 4.600 to $54.998^{\circ}$ & 3.530 to $51.992^{\circ}$ & 3.686 to $73.350^{\circ}$ \\
\hline Miller Indices & $\begin{array}{c}-22 \leq h \leq 22,-23 \leq k \leq 22 \\
-9 \leq l \leq 8\end{array}$ & $\begin{array}{c}-11 \leq h \leq 11,-12 \leq k \leq 12 \\
-14 \leq l \leq 14\end{array}$ & $\begin{array}{c}-5 \leq h \leq 11,-17 \leq k \leq 17 \\
-18 \leq l \leq 18\end{array}$ \\
\hline Reflections Collected & 26288 & 15284 & 20949 \\
\hline Independent Reflections & $\begin{array}{c}4857\left[R_{\text {int }}=0.0644\right. \\
\left.R_{\text {sigma }}=0.0554\right]\end{array}$ & $\begin{array}{c}4131\left[R_{\text {int }}=0.0545\right. \\
\left.R_{\text {sigma }}=0.0495\right]\end{array}$ & $\begin{array}{c}6792\left[R_{\text {int }}=0.0223\right. \\
\left.R_{\text {sigma }}=0.0231\right]\end{array}$ \\
\hline Data/restraints/Parameters & $4857 / 4 / 288$ & $4131 / 6 / 306$ & $6792 / 7 / 219$ \\
\hline GoF & 1.035 & 1.025 & 1.034 \\
\hline Final $R$ Factors $[I \geq 2 \sigma(I)]$ & $R_{1}=0.0605, w R_{2}=0.1426$ & $R_{1}=0.0461, w R_{2}=0.1149$ & $R_{1}=0.0358, w R_{2}=0.1059$ \\
\hline Final $R$ Factors [All Data] & $R_{1}=0.1174, w R_{2}=0.1701$ & $R_{1}=0.0609, w R_{2}=0.1250$ & $R_{1}=0.0462, w R_{2}=0.1138$ \\
\hline $\begin{array}{l}\text { Largest Diff. Peak/Hole, } \\
\qquad e^{-3}\end{array}$ & $0.29 /-0.27$ & $0.45 /-0.41$ & $0.37 /-0.51$ \\
\hline
\end{tabular}


The MBI-phosphite crystal belongs to monoclinic symmetry (space group $\mathrm{P} 2{ }_{1} / \mathrm{c}$ ). The unit cell contains four formula units of $\left(\mathrm{C}_{8} \mathrm{H}_{9} \mathrm{~N}_{2}\right)_{2}{ }^{*}\left(\mathrm{PO}_{3} \mathrm{H}_{2}\right)_{2}{ }^{*} \mathrm{H}_{2} \mathrm{O}$ and includes eight MBI molecules, eight molecules of phosphorous acid, and four molecules of water. In MBI crystal, the MBI molecule $\mathrm{C}_{8} \mathrm{H}_{8} \mathrm{~N}_{2}$ includes eight hydrogen atoms. However, benzimidazoles are known to be amphoteric, and when interacting with a strong acid, a chemical reaction of protonation occurs: In MBI-phosphite crystal, the MBI molecule attaches a hydrogen ion and turns into a cation $\mathrm{C}_{8} \mathrm{H}_{9} \mathrm{~N}_{2}(\mathrm{MBI}+\mathrm{H})^{+}$(see Figure 2). Cation $(\mathrm{MBI}+\mathrm{H})^{+}$formation is confirmed also by XRD analysis in MBI-phosphate- 1 and MBI-phosphate-2. The acid molecule $\mathrm{H}_{3} \mathrm{PO}_{3}$ or $\mathrm{H}_{3} \mathrm{PO}_{4}$ loses a hydrogen atom and becomes an anion $\mathrm{H}_{2} \mathrm{PO}_{3}{ }^{-}$or $\mathrm{H}_{2} \mathrm{PO}_{4}{ }^{-}$. Proton forms a valence bond with one of the nitrogen atoms of the imidazole ring [41].

\section{Molecule MBI}

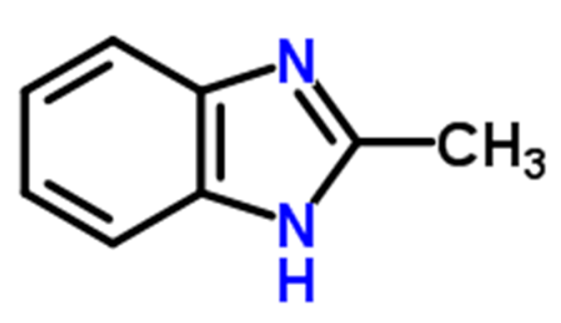

\section{Cation $(\mathrm{MBI}+\mathrm{H})^{+}$}

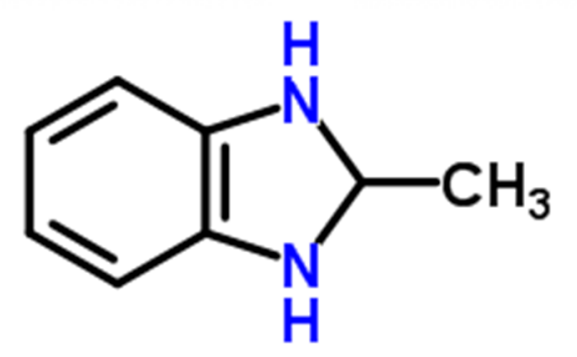

Figure 2. Structural formulas of MBI molecule and cation $(\mathrm{MBI}+\mathrm{H})^{+}$.

In the unit cell of the MBI-phosphite crystal, half of the $(\mathrm{MBI}+\mathrm{H})+$ cations lies almost in the ab plane, and the other at an angle of $\sim 15^{\circ}$ to this plane (Figure $3 \mathrm{a}$ ). The crystal structure consists of goffered layers in the ab plane. There are 24 non-equivalent positions of hydrogen atom, 8 of them fall on hydrogen bonds. So, there are 8 different $\mathrm{N} \ldots \mathrm{H}-\mathrm{O}$ or $\mathrm{O} \ldots \mathrm{H}$ - O hydrogen bonds (lengths 2.6-2.9 $\AA$ ) forming a complicated three-dimensional net. Cations (MBI $+\mathrm{H})^{+}$connected by the $\mathrm{HPO}_{3}{ }^{2-}$ tetrahedrons and the water molecules form zig-zag chains along the a-axis (Figure $3 \mathrm{~b}$ ). Protons $\mathrm{H}^{+}$in two hydrogen bonds connecting two $\mathrm{HPO}_{3}{ }^{2-}$ tetrahedra are placed near the different tetrahedrons. Protons in the hydrogen bonds between the imidazole ring and the tetrahedron are placed near the imidazole ring. There are also the hydrogen bonds between the water molecules and the tetrahedrons formed by protons of the water molecules. In such bonds, proton is placed near the water. The same arrangement of the protons in the hydrogen bonds is observed in MBI-phosphate-1 and MBI-phosphate-2. In contrast to MBI crystal in new crystals the N ... H - N hydrogen bonds between the MBI molecules are absent.

The MBI-phosphate- 1 crystal belongs to triclinic symmetry (space group P $\overline{1}$ ). The unit cell contains two formula units of $\left(\mathrm{C}_{8} \mathrm{H}_{9} \mathrm{~N}_{2}\right)_{2}{ }^{*}\left(\mathrm{PO}_{4} \mathrm{H}_{2}\right)_{2}{ }^{*} \mathrm{H}_{2} \mathrm{O}$ and includes four MBI molecules, four molecules of phosphoric acid, and two molecules of water. Analogously to MBI-phosphite, in the MBI-phosphate-1 for each MBI molecule there is one molecule of acid. There are 10 non-equivalent $\mathrm{N}$... H-O or O ... $\mathrm{H}-\mathrm{O}$ hydrogen bonds (lengths 2.5-2.8 $\AA$ ) in crystal structure. Cations $(\mathrm{MBI}+\mathrm{H})^{+}$form goffered layers parallel to the (101) plane (Figure 4). In one layer there are two non-equivalent positions for the cations. In these positions the directions, along which the MBI cations are elongated, are close to the b-axis but differ by angle $\sim 31^{\circ}$. In adjacent layers the MBI cations are rotated at $180^{\circ}$ around an axis perpendicular to their plane. Thus, the situation is different from the MBI crystal [18] where the molecules in the same layer are rotated $180^{\circ}$, and the molecules in the neighboring layers are rotated $90^{\circ}$ relative to each other. The hydrogen bonds in MBI-phosphate- 1 crystal form a two-dimensional (2D) network in a layer. There are also interlayer hydrogen bonds connecting the phosphorous tetrahedra. They form broken chains. The hydrogen bonds of the chain link connect only four layers. 
(a)

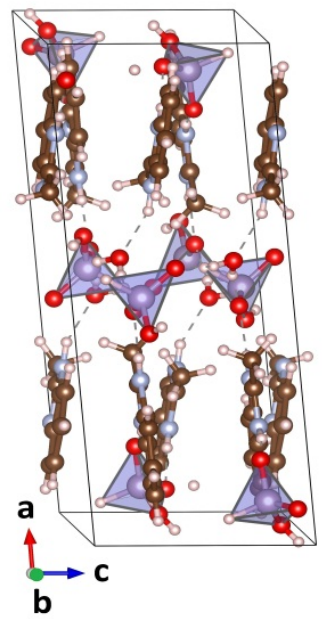

(b)
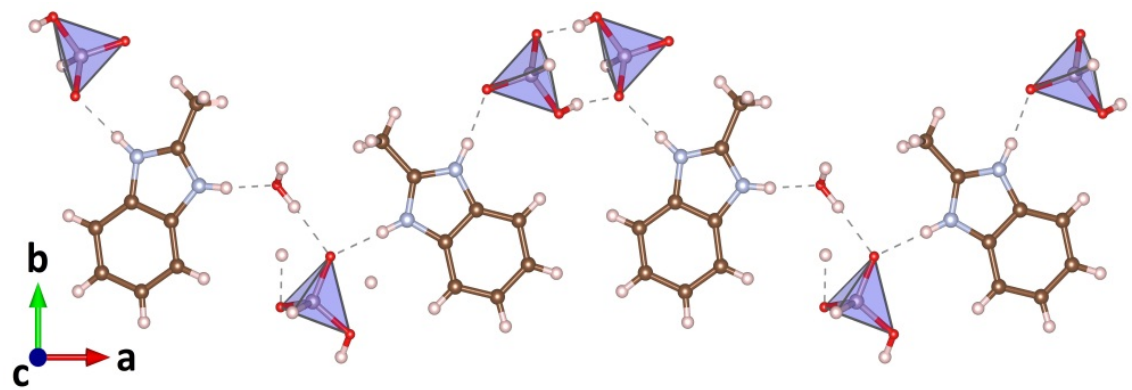

Figure 3. Crystal structure of MBI-phosphite $\left(\mathrm{C}_{8} \mathrm{H}_{9} \mathrm{~N}_{2}\right)_{2}\left(\mathrm{H}_{2} \mathrm{PO}_{3}\right)_{2} \mathrm{H}_{2} \mathrm{O}$ (red balls are oxygen atoms, brown the carbons, gray the nitrogens, white the hydrogens, lilac the phosphorus). (a). Zig-zag chain along the a-axis in the structure (b).

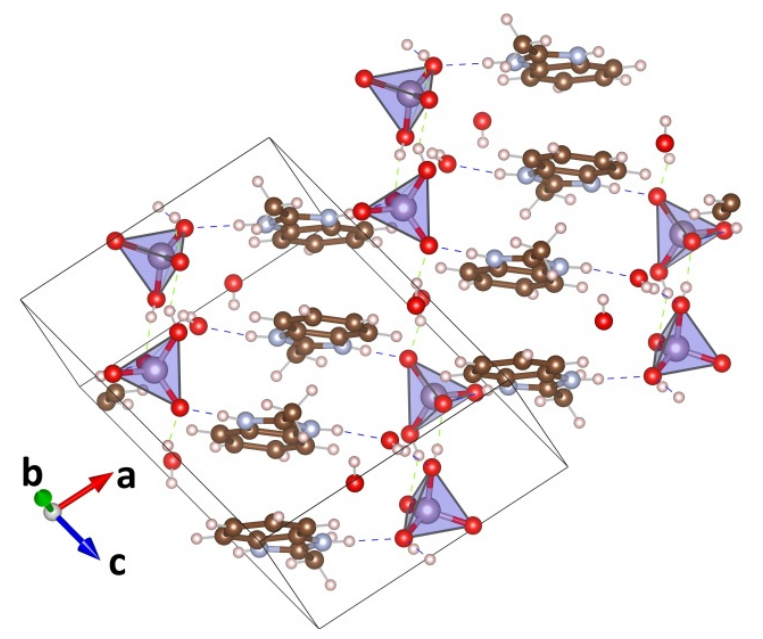

Figure 4. Crystal structure of MBI-phosphate- $1\left(\mathrm{C}_{8} \mathrm{H}_{9} \mathrm{~N}_{2}\right)_{2}\left(\mathrm{H}_{2} \mathrm{PO}_{4}\right)_{2} \mathrm{H}_{2} \mathrm{O}$ (red balls are oxygen atoms, brown the carbons, gray the nitrogens, white the hydrogens, lilac the phosphorus).

The MBI-phosphate-2 crystal, like MBI-phosphate-1, belongs to triclinic symmetry (space group $\mathrm{P} \overline{1})$. The unit cell contains two formula units of $\left(\mathrm{C}_{8} \mathrm{H}_{9} \mathrm{~N}_{2}\right)^{*}\left(\mathrm{PO}_{4} \mathrm{H}_{2}\right)^{*}\left(\mathrm{PO}_{4} \mathrm{H}_{3}\right)^{*} \mathrm{H}_{2} \mathrm{O}$ and includes two MBI molecules, four molecules of phosphoric acid, and two molecules of water. In contrast to MBI-phosphite and MBI-phosphate-1, in MBI-phosphate-2 for each MBI molecule there are two molecules of acid, and only one of them is deprotonated. There are layers, perpendicular to the b-axis, formed by the phosphoric acid and the water molecules (see Figure $5 a, b$ ). These inorganic layers are 
connected through the molecules of 2-methylbenzimidazole with the hydrogen bonds $\mathrm{N} \ldots \mathrm{H}$ - O, directed along the [011] and [010] axes (see Figure 5c).

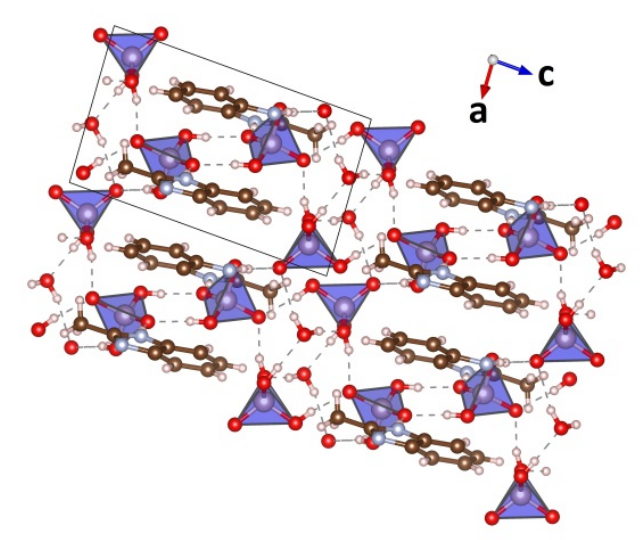

(a)

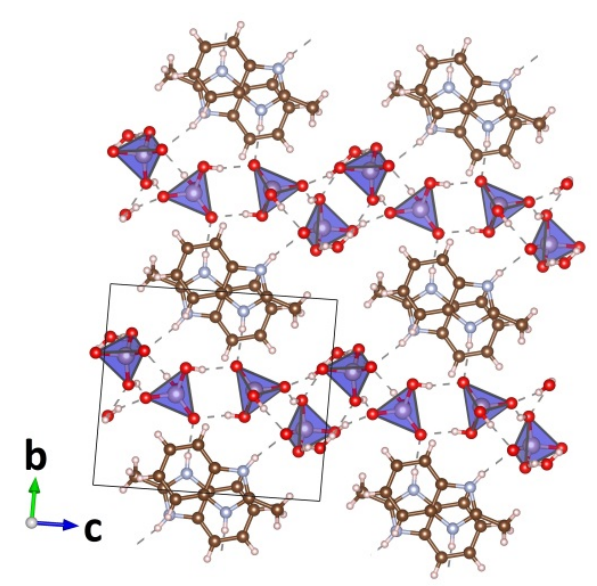

(b)

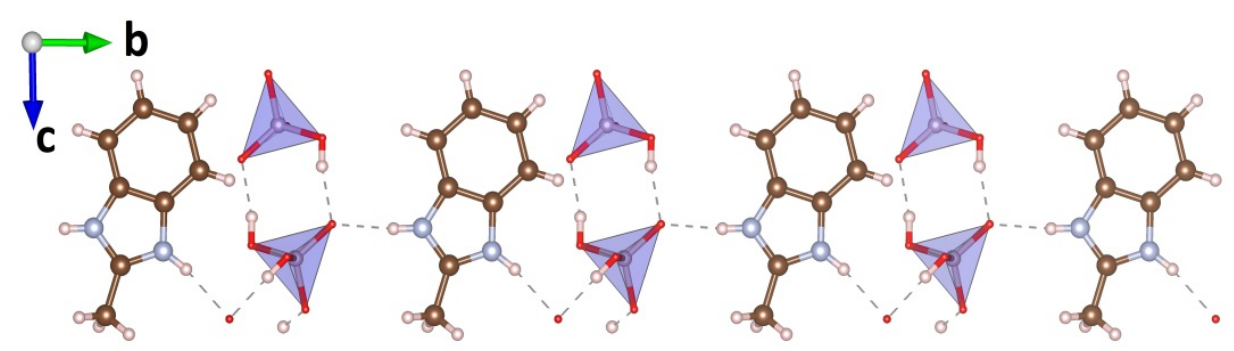

(c)

Figure 5. Crystal structure of MBI-phosphate-2 $\left(\mathrm{C}_{8} \mathrm{H}_{9} \mathrm{~N}_{2}\right)^{*}\left(\mathrm{PO}_{4} \mathrm{H}_{2}\right)^{*}\left(\mathrm{PO}_{4} \mathrm{H}_{3}\right)^{*} \mathrm{H}_{2} \mathrm{O}$ (red balls are oxygen atoms, brown the carbons, gray the nitrogens, white the hydrogens, lilac the phosphorus) (a,b) and a chain along the b-axis (c).

A comparison of the lengths and the angles between bonds of the MBI molecule in MBI crystal [42], and in the crystals studied in this work (Table S17 in SM) showed that the protonation led to noticeable changes of the imidazole ring. In particular, in the new crystals, the bond lengths of N (1) - C(2) and $\mathrm{C}(2)-\mathrm{N}(2)$ bonds of the imidazole ring were $\sim 1 \%$ shorter than in the MBI crystals. The angle in the imidazole ring, whose apex is the nitrogen atom, increased from $106^{\circ}$ in the MBI crystal to $109^{\circ}$, and the angle N-C-N decreased from $113^{\circ}$ to $109^{\circ}$ (see Table S17 in SM). Note that similar changes caused by protonation were observed in organometallic complexes [43]. This provides additional confirmation of proton transfer from the acid tetrahedron to the MBI molecule in the new crystals.

\subsection{Powder XRD}

The sufficiently good Rietveld fit quality is illustrated in Figure 6 for MBI-phosphate- 1 and MBI-phosphite. The coordinates and overall isotropic temperature factors of atoms of MBI-phosphite refined by Rietveld method from powder data and the selected calculated interatomic distances are given in Tables S11 and S13 of SM. Reached values of agreement factors are summarized in Table S16 of SM. 

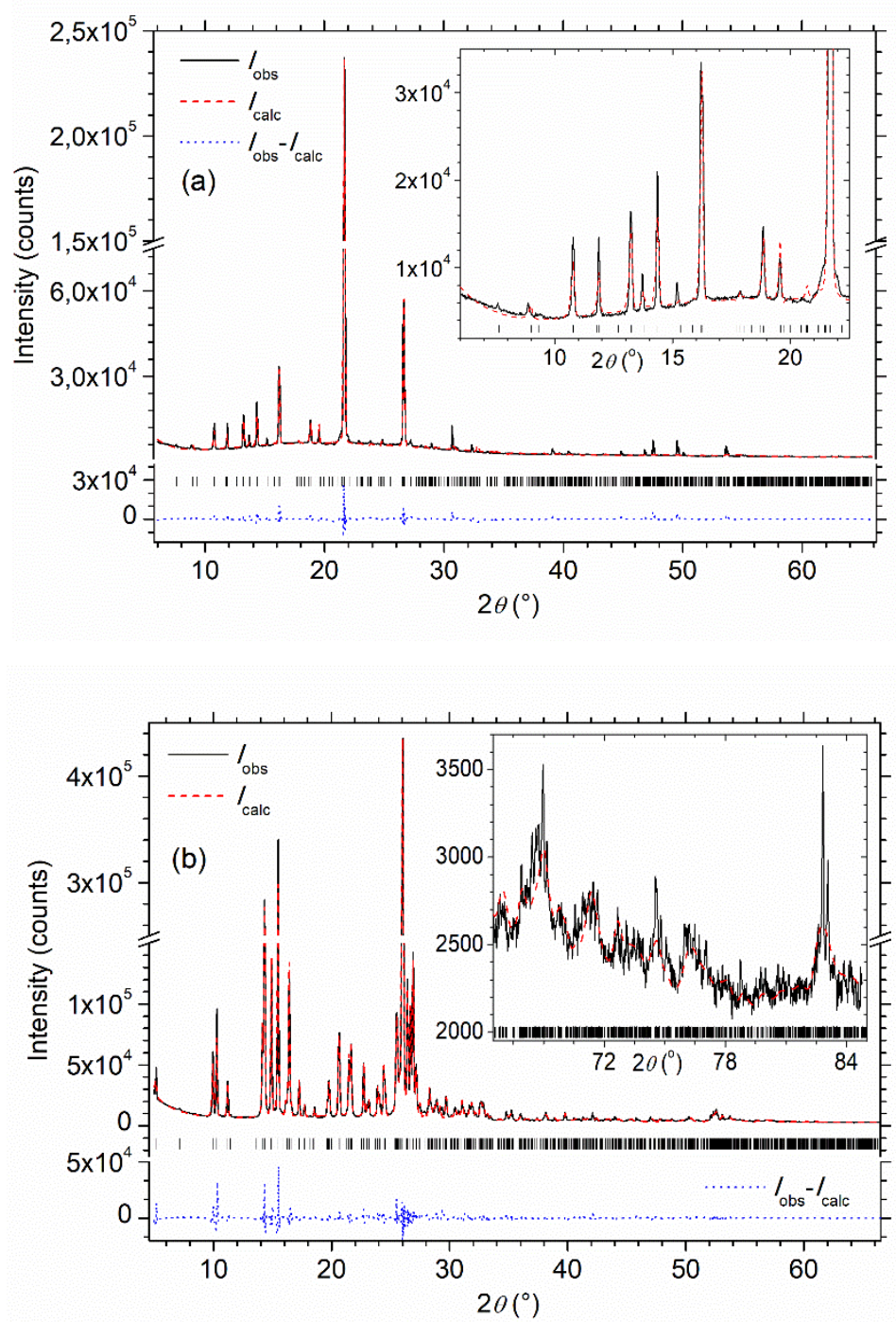

Figure 6. (a) MBI-phosphate-1, (b) MBI-phosphite. Experimental XRD pattern $\left(\mathrm{I}_{\mathrm{obs}}\right)$, superimposed with the one calculated by means of Rietveld fitting $\left(\mathrm{I}_{\text {calc }}\right)$. The $\mathrm{I}_{\mathrm{obs}}-\mathrm{I}_{\text {calc }}$ difference diagram is shown below. Angle positions of the Bragg reflections calculated according to refined unit parameters are indicated by vertical bars. The inserts show the experimental and calculated XRD patterns in a low-angle range $2 \theta<22.5^{\circ}$ for MBI-phosphate- 1 (a) and a high-angle range $2 \theta>66.5^{\circ}$ of the MBI-phosphite XRD pattern (b) on a larger scale.

For the powder XRD measurements and the single crystal XRD investigation of the MBI-phosphate-1, even without refining of atomic coordinates by the Rietveld method, a rather low value of weighted profile factor $R_{\mathrm{wp}}=12.57 \%$ was obtained, proving the rather good quality of the XRD pattern fitting (Figure 6a). Reached low value of Bragg factor $R_{B}=4.34 \%$ evidenced the correctness of the MBI-phosphate-1 structure model (see, for example, [33] for definition of the agreement factors). Even better agreement factors and XRD pattern fitting quality (Figure $6 \mathrm{~b}$ ) were obtained for MBI-phosphite $\left(R_{w p}=9.72 \%, R_{B}=1.83 \%\right)$, where atomic coordinates obtained from single crystal investigation were refined by the Rietveld method. In spite of the single crystals being chosen from the same powder, which was investigated by means of powder XRD, the unit cell parameters and atomic coordinates obtained in the Rietveld refinement of the powder data differ slightly, but more than two values of estimated standard deviation (ESD) from those obtained on a single crystal, although they are close. For triclinic MBI-phosphate- 1 and monoclinic MBI-phosphite powders, $a=9.682(1) \AA$, $\mathrm{b}=9.827(9) \AA, \mathrm{c}=11.804(2) \AA, \alpha=88.98(7)^{\circ}, \beta=78.15(10)^{\circ}, \gamma=87.37(9)^{\circ}$, and $\mathrm{a}=17.1974(3) \AA$, 
$\mathrm{b}=17.7198(6) \AA, \mathrm{c}=7.01193(8) \AA, \beta=94.878(2)^{\circ}$, respectively (see the unit cell parameters from single crystal investigation in Table 1 for comparison). The atomic coordinates of MBI-phosphite obtained from the single crystal and powder XRD data are shown together for comparison in Table S11 of SM. The differences in structural parameters can be explained by the fact that in the powder experiment all information is averaged over all crystallites involved in the reflection of $\mathrm{X}$-rays, and the information obtained in the single crystal experiment is individual for each single crystal. Nevertheless, the interatomic distances calculated from the powder XRD (Table S13 of SM) lie in allowed range and agree with the single crystal results.

Thus, the data of XRD obtained on powders confidently confirm the structure model determined by XRD analysis of single crystals.

\subsection{Elemental Analysis}

Figure 7 demonstrates the images obtained by SEM of MBI-phosphite (a) and MBI-phosphate-2 (c) single crystals and their EDX spectra (b) and (d), respectively.
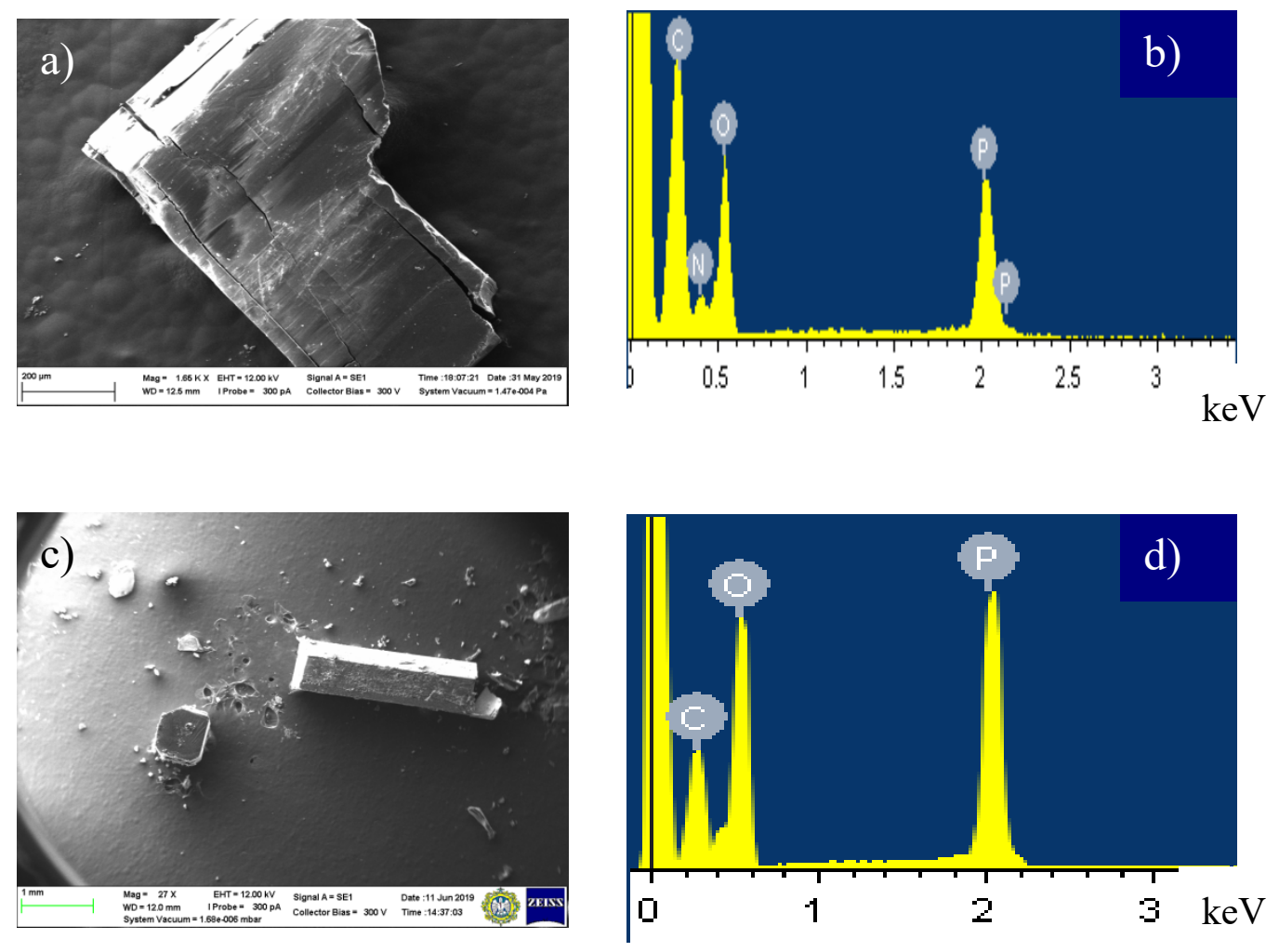

Figure 7. The images of MBI-phosphite (a) and MBI-phosphate-2 (c) single crystals, obtained by SEM, X-ray spectroscopy (EDX) spectra of MBI-phosphite (b) and MBI-phosphate-2 (d), respectively.

EDX spectra confirm the presence of $\mathrm{C}, \mathrm{N}, \mathrm{O}$, and P elements and the absence of other elements in the crystals. Hydrogen atoms were not registered in the framework of the method used. The experimental and calculated elemental composition are presented in SM (Table S18). The experimental values of phosphorous concentration are smaller than the calculated ones, most probably due to the low energy resolution of the detector in the region of light elements and the possible presence of an organic layer on the surface. Note that the crystals were not covered by a conductive layer and were studied without cleaning. The spectrum of MBI-phosphite, shown in Figure 7b, is similar to MBI-phosphate- 1 because the difference in their composition is only two oxygen atoms. For the MBI-phosphate-2 (Figure 7d), an increase of the phosphorus concentration in accordance with their composition was observed. 


\subsection{Raman Spectroscopy}

Raman spectra of organic molecular crystals usually consist of a number of lines originated from internal molecular vibrations of different nature. This makes it possible to use Raman spectroscopy for checking the molecular compositions of crystals. Figure 8 presents Raman spectra of MBI-phosphite powder (T64000 Advanced Research Raman System) and single crystals of MBI, MBI-phosphate-1, and MBI-phosphate-2 (Alpha 300R confocal microscope). Spectra of single crystals were obtained in geometry of backscattering for two orthogonal polarizations of incident light without output polarizer. Because of low symmetry of MBI-phosphate-1, MBI-phosphate-2 $\left(\mathrm{C}_{\mathrm{i}}(\mathrm{P} \overline{1})\right)$, and MBI $\left(\mathrm{C}_{\mathrm{s}}(\mathrm{Pn})\right)$ crystals, the spectra in each crystal have the same number of lines for both polarizations with approximately the same intensity. Table 2 reveals Raman shifts in $\mathrm{cm}^{-1}$ for lines observed in MBI, MBI-phosphite, MBI-phosphate- 1, and MBI-phosphate-2.

Experimental Raman and Fourier-transform infrared (FTIR) spectra of MBI crystal powder and their interpretation have been presented in [44]. Theoretical analysis based on density functional theory (DFT) method has shown that the vibration spectrum of MBI molecule $\left(\mathrm{C}_{\mathrm{S}}(\mathrm{m})\right.$ symmetry) consists of 48 modes corresponding, in particular, to the stretching vibrations of carbon-hydrogen valence bonds with frequencies of about $3000 \mathrm{~cm}^{-1}$, carbon-nitrogen, and carbon-carbon valence bonds in the region of $600-1700 \mathrm{~cm}^{-1}$, bendings of the benzene and imidazole rings in the region of $100-1200 \mathrm{~cm}^{-1}$ and others. There were 32 of oscillation modes related to in-plane (labelled as $\mathrm{A}^{\prime}$ ) and 16 to out-of-plane $\left(\mathrm{A}^{\prime \prime}\right)$ deformations of molecule. From the predicted 48 modes, 32 were detected experimentally in [44], among them 25 in Raman and 19 modes in FTIR spectra. There were 12 modes detected in both spectra that has been confirmed the noncentrosymmetric structure of the MBI crystal.

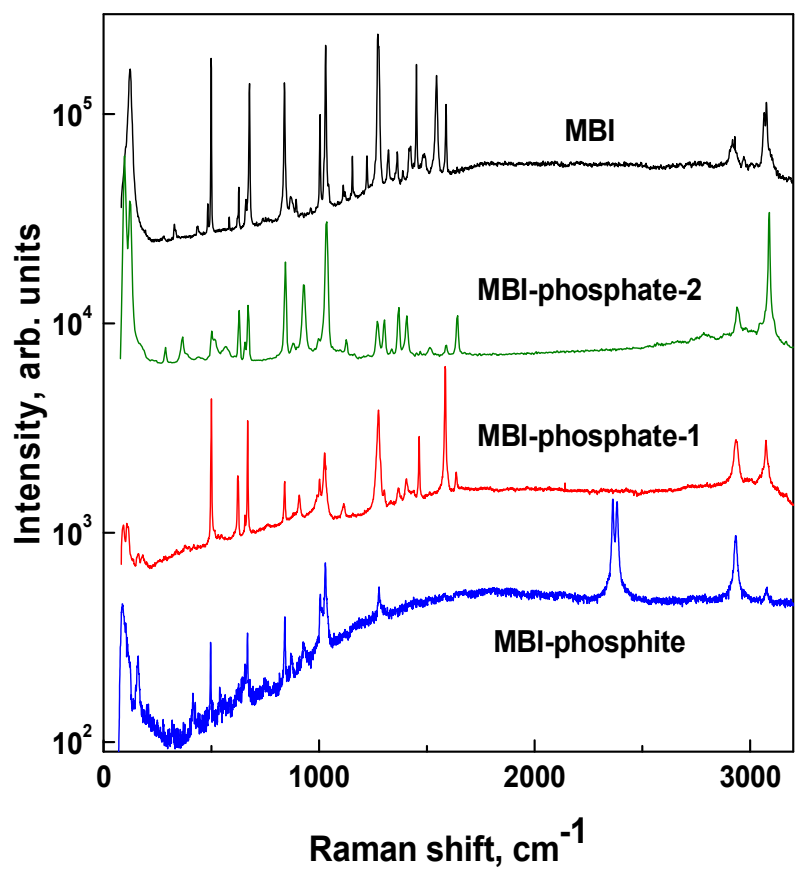

Figure 8. Raman spectra of MBI, MBI-phosphate-1, MBI-phosphate-2 single crystals, and MBI-phosphite powder. For convenience, the spectra are shifted along the vertical axis. The intensity of scattered light is in logarithmic scale.

Raman spectrum of the MBI single crystal obtained in our work (Figure 8) is similar to that of [44]. The positions of the 10 strongest lines coincide with accuracy of $2 \mathrm{~cm}^{-1}$. Experimentally, we observed 42 lines. Among them there were lines which were observed in Raman and FTIR spectra in [44], and also seven lines which were predicted theoretically but not observed experimentally before. In Table 2 these lines are marked by *. 
Large numbers of these lines, observed in Raman spectra of three new crystals (Figure 8, Table 2), correspond well to vibrations of the MBI molecule. Some of these lines (characteristic lines) have the same Raman shift as in the MBI crystal. Difference in Raman shifts for other lines may be of the order of $10 \mathrm{~cm}^{-1}$. That may be attributed to some modification in interaction between molecules in these crystals. Another reason may be the effect of imidazole ring protonation [43].

Table 2. Raman shifts in $\mathrm{cm}^{-1}$ for lines observed in MBI, MBI-phosphite, MBI-phosphate-1, and MBI-phosphate-2 samples. Last column shows interpretation of lines for MBI from [44]. Lines marked by * have been observed for the first time. Abbreviations: vs - very strong, s - strong, $\mathrm{m}-\mathrm{medium}, \mathrm{w}-$ weak, $b$ - broad, $\Gamma$ - out-of-plane bending, $\delta$ - in-plane bending, $v$ - stretching, $M-$ methyl group.

\begin{tabular}{|c|c|c|c|c|c|}
\hline № & MBI & MBI-Phosphite & MBI-Phosphate-1 & MBI-Phosphate-2 & Assignment \\
\hline 1 & $\begin{array}{l}3065 \mathrm{~m} \\
3075 \mathrm{~m}\end{array}$ & $3076 \mathrm{~s}$ & $\begin{array}{l}3073 s \\
3085 s\end{array}$ & $3086 s$ & MBI: $v_{\mathrm{CH}}$ \\
\hline 2 & $2968 m$ & & $2984 w$ & & MBI: $\mathrm{M} v_{\mathrm{CH}}$ \\
\hline 3 & $\begin{array}{l}2919 m \\
2929 m\end{array}$ & $2934 \mathrm{~s}$ & $\begin{array}{l}2933 s \\
2940 s\end{array}$ & $2938 s$ & MBI: $\mathrm{M} \vee_{\mathrm{CH}}$ \\
\hline 4 & & $\begin{array}{l}2363 \mathrm{~s}, \\
2382 \mathrm{~s}\end{array}$ & & & $\begin{array}{c}\mathrm{H}_{3} \mathrm{PO}_{3}: v_{\mathrm{PH}} \\
{[5,20,45-47]}\end{array}$ \\
\hline 5 & & $1637 \mathrm{~m}$ & $1637 \mathrm{~m}$ & $1637 \mathrm{~s}$ & $\delta_{\mathrm{H} 2 \mathrm{O}}[48-50]$ \\
\hline 6 & $1589 \mathrm{~m}$ & $1583 \mathrm{~s}$ & $1585 s$ & $1584 \mathrm{~m}$ & MBI: $v_{\mathrm{CC}}$ \\
\hline 7 & $1545 \mathrm{~s}$ & & & & $\begin{array}{c}\text { MBI: } v_{\mathrm{CN}} \text { (double } \\
\text { bond) }+v_{\mathrm{CC}}\end{array}$ \\
\hline 8 & & $1517 w$ & $1515 w$ & $1512 \mathrm{~m}$ & $\delta_{\mathrm{H} 2 \mathrm{O}}[48-50]$ \\
\hline 9 & $\begin{array}{l}1472 \mathrm{w} \\
1488 \mathrm{~m}\end{array}$ & & & & $\begin{array}{c}\text { MBI: }{ }^{\mathrm{M}} \delta_{\mathrm{CH} 2}+\Gamma_{\mathrm{CCCN}}+ \\
\delta_{\mathrm{CCH}}\end{array}$ \\
\hline 10 & $\begin{array}{l}1438 \mathrm{~m} \\
1452 \mathrm{~s}\end{array}$ & $1466 \mathrm{~s}$ & $\begin{array}{l}1436 \mathrm{w} \\
1464 \mathrm{~s}\end{array}$ & $1466 \mathrm{~s}$ & MBI: $\delta_{\mathrm{CCH}}+v_{\mathrm{CC}}$ \\
\hline 11 & $1425 \mathrm{~m}$ & & & & $\begin{array}{c}{ }^{*} \mathrm{MBI}: \delta_{\mathrm{CNH}}+v_{\mathrm{CN}} \\
+v_{\mathrm{CC}}+\delta_{\mathrm{CCH}}\end{array}$ \\
\hline 12 & $1418 w$ & $1408 \mathrm{~s}$ & $1405 \mathrm{~m}$ & $1403 \mathrm{~s}$ & MBI: $\mathrm{M} \delta_{\mathrm{CH} 2}+\delta_{\mathrm{CCH}}$ \\
\hline 13 & $1363 m$ & $1369 \mathrm{~m}$ & $1368 w$ & $1364 \mathrm{~s}$ & $\begin{array}{c}\text { MBI: } v_{\mathrm{CC}}+v_{\mathrm{CN}^{+}} \\
\mathrm{M} \delta_{\mathrm{CH} 2}\end{array}$ \\
\hline 14 & $1322 \mathrm{~m}$ & & $1332 w$ & $1337 \mathrm{~m}$ & MBI: $\delta_{\mathrm{CCH}}+v_{\mathrm{CN}}$ \\
\hline 15 & & & $1303 w$ & $1302 s$ & $\delta_{\mathrm{OH}} \ldots \mathrm{O}[51]$ \\
\hline 16 & $1272 s$ & $1276 \mathrm{~s}$ & $1276 s$ & $1266 \mathrm{~s}$ & MBI: $v_{\mathrm{CN}}+v_{\mathrm{CC}}+\delta_{\mathrm{CCH}}$ \\
\hline 17 & $1222 \mathrm{~m}$ & & & $1224 w$ & $\begin{array}{c}\text { MBI: } \\
\delta_{\mathrm{CCH}}+v_{\mathrm{CN}}+ \\
v_{\mathrm{CC}} \\
\end{array}$ \\
\hline 18 & $1155 \mathrm{~m}$ & $1157 \mathrm{~m}$ & $1156 w$ & $1160 \mathrm{~m}$ & ${ }^{*} \mathrm{MBI}: \delta_{\mathrm{CCH}}$ \\
\hline 19 & $\begin{array}{l}1113 \mathrm{~m} \\
1120 \mathrm{~m}\end{array}$ & $1119 \mathrm{~s}$ & $1115 \mathrm{~m}$ & $1121 \mathrm{~s}$ & MBI: $\delta_{\mathrm{CCH}}+v_{\mathrm{CC}}$ \\
\hline 20 & $1044 m$ & & & & MBI: $\delta_{\mathrm{CCH}}+\Gamma_{\mathrm{NCCH}}$ \\
\hline 21 & $1030 \mathrm{~s}$ & $1028 \mathrm{~s}$ & $1026 \mathrm{~s}$ & $1028 v s$ & MBI: $v_{\mathrm{CC}}+v_{\mathrm{CN}}$ \\
\hline 22 & $1004 \mathrm{~s}$ & $1006 \mathrm{~s}$ & $1002 \mathrm{~m}$ & $1004 w$ & MBI: $v_{\mathrm{CC}}+\delta_{\mathrm{CCH}}$ \\
\hline 23 & & $991 \mathrm{~m}$ & $990 w$ & $991 w$ & $v_{\mathrm{OPO}}[45,52]$ \\
\hline 24 & $960 w$ & & & & ${ }^{*} \mathrm{MBI}: \Gamma_{\mathrm{HCCH}}+\Gamma_{\mathrm{CCCH}}$ \\
\hline 25 & & $933 \mathrm{~m}$ & $908 \mathrm{~m}$ & $924 \mathrm{~s}$ & $v_{\mathrm{OPO}}[5,47,49,53]$ \\
\hline 26 & $921 w$ & & & & MBI: $\Gamma_{\mathrm{HCCH}}+\Gamma_{\mathrm{CCCH}}$ \\
\hline 27 & $893 \mathrm{~m}$ & & $897 w$ & & MBI: $\delta_{\mathrm{CCC}}+\delta_{\mathrm{CCH}}$ \\
\hline
\end{tabular}


Table 2. Cont.

\begin{tabular}{|c|c|c|c|c|c|}
\hline № & MBI & MBI-Phosphite & MBI-Phosphate-1 & MBI-Phosphate-2 & Assignment \\
\hline 28 & $868 \mathrm{~m}$ & $867 \mathrm{~m}$ & & $878 w$ & $\begin{array}{c}{ }^{*} \mathrm{MBI}: \Gamma_{\mathrm{CCCH}}+\Gamma_{\mathrm{HCCN}} \\
+\Gamma_{\mathrm{HCCH}}+\Gamma_{\mathrm{CCCH}}\end{array}$ \\
\hline 29 & $839 \mathrm{~s}$ & $840 \mathrm{~s}$ & $840 \mathrm{~s}$ & $839 \mathrm{~s}$ & MBI: $v_{C C}$ \\
\hline 30 & $764 w$ & & $761 w$ & $768 w$ & MBI: $\Gamma_{\mathrm{CCCH}}+\Gamma_{\mathrm{CCCC}}$ \\
\hline 31 & $741 \mathrm{~m}$ & $745 w$ & & & MBI: $\Gamma_{\mathrm{CCCH}}+\Gamma_{\mathrm{HCCN}}$ \\
\hline 32 & $677 \mathrm{~s}$ & $667 \mathrm{~s}$ & $669 \mathrm{~s}$ & $667 \mathrm{~s}$ & $\begin{array}{c}\text { MBI: } v_{\mathrm{CC}}+\delta_{\mathrm{CCC}}+ \\
\delta_{\mathrm{CCN}}\end{array}$ \\
\hline 33 & $657 \mathrm{~m}$ & $656 \mathrm{~m}$ & $656 w$ & $652 \mathrm{~s}$ & $\begin{array}{c}{ }^{*} \mathrm{MBI}: \Gamma_{\mathrm{CNCN}}+\Gamma_{\mathrm{HCCN}} \\
+\Gamma_{\mathrm{CCCN}}+\Gamma_{\mathrm{HNCN}}\end{array}$ \\
\hline 34 & $\begin{array}{l}623 \mathrm{w} \\
628 \mathrm{~m}\end{array}$ & $624 \mathrm{~s}$ & $623 \mathrm{~m}$ & $624 \mathrm{~s}$ & $\begin{array}{c}\text { MBI: } \delta_{\mathrm{CCN}}+\delta_{\mathrm{CCC}}+ \\
v_{\mathrm{CC}}\end{array}$ \\
\hline 35 & $582 \mathrm{~s}$ & & & $581 w$ & $\begin{aligned}{ }^{*} \mathrm{MBI}: & \Gamma_{\mathrm{CCCC}}+\Gamma_{\mathrm{CCCN}} \\
& +\Gamma_{\mathrm{CCCH}}\end{aligned}$ \\
\hline 36 & & & $546 w$ & $\begin{array}{l}546 \mathrm{w} \\
566 \mathrm{~m}\end{array}$ & $\begin{array}{c}\mathrm{H}_{3} \mathrm{PO}_{4}: \mathrm{PO}_{4} \text { bending } \\
\left(v_{4}\right)[49 ; 52]\end{array}$ \\
\hline 37 & & $537 \mathrm{~m}$ & & & $\begin{array}{c}\mathrm{H}_{3} \mathrm{PO}_{3}: \mathrm{PO}_{3} \text { asym. } \\
\text { bending }[5,54]\end{array}$ \\
\hline 38 & & & $516 w$ & $513 \mathrm{sb}$ & $\mathrm{H}_{3} \mathrm{PO}_{4}[53,55]$ \\
\hline 39 & $499 \mathrm{~s}$ & $497 \mathrm{~s}$ & $500 \mathrm{~s}$ & $497 \mathrm{~s}$ & $\begin{array}{c}\text { MBI: } \delta_{\mathrm{CCC}}+v_{\mathrm{CC}}+ \\
v_{\mathrm{CN}}\end{array}$ \\
\hline 40 & $483 \mathrm{~m}$ & $483 w$ & & $483 w$ & $\begin{array}{c}{ }^{*} \mathrm{MBI}: \delta_{\mathrm{CCN}}+\delta_{\mathrm{CCC}}+ \\
v_{\mathrm{CC}}\end{array}$ \\
\hline 41 & $435 \mathrm{~m}$ & $435 w$ & & $435 w$ & $\begin{array}{c}\text { MBI: } \Gamma_{\mathrm{CCCC}}+\Gamma_{\mathrm{CCCH}}+ \\
\Gamma_{\mathrm{CCNH}}+\Gamma_{\mathrm{CCNC}} \\
\end{array}$ \\
\hline 42 & & $415 \mathrm{~m}$ & $419 w$ & & $\begin{array}{l}\text { Water libration? lattice } \\
\text { modes? }\end{array}$ \\
\hline 43 & & & $379 w$ & $\begin{array}{c}364 \mathrm{~s} \\
383 \mathrm{mb}\end{array}$ & $\begin{array}{c}\mathrm{H}_{3} \mathrm{PO}_{4}: \mathrm{PO}_{4} \text { sym. } \\
\text { bending }[53,56]\end{array}$ \\
\hline 44 & $\begin{array}{l}329 w \\
334 m\end{array}$ & $318 \mathrm{~m}$ & $339 w$ & $324 w$ & MBI: $\Gamma_{\mathrm{CCCN}}+\Gamma_{\mathrm{CCNH}}$ \\
\hline 45 & $274 \mathrm{~m}$ & $279 \mathrm{~m}$ & $288 w$ & $285 \mathrm{~s}$ & MBI: $\delta_{\mathrm{CCN}}$ \\
\hline 46 & $123 \mathrm{vs}$ & $\begin{array}{l}115 \mathrm{w} \\
160 \mathrm{~s}\end{array}$ & $\begin{array}{l}114 w \\
159 w\end{array}$ & $122 \mathrm{vs}$ & $\begin{array}{c}\text { MBI: } \Gamma_{\mathrm{CCCN}}+\Gamma_{\mathrm{HCCN}} \\
\text { lattice modes? }\end{array}$ \\
\hline 47 & & $89 \mathrm{sb}$ & $\begin{array}{l}90 \mathrm{~m}, \\
108 \mathrm{~m}\end{array}$ & $96 v s$ & $\begin{array}{c}{ }^{*} \mathrm{MBI}: \Gamma_{\mathrm{HCCN}} ? \text { lattice } \\
\text { modes? }\end{array}$ \\
\hline
\end{tabular}

It is worth noting that the strong line (No. 7, Table 2) at $1545 \mathrm{~cm}^{-1}$ arising due to the stretching vibration of the carbon-nitrogen double valence bond in the imidazole ring [44], which presents in MBI spectrum, is absent in spectra of the new crystals. This is in excellent agreement with the results of XRD study of crystal structure. According to XRD analysis, all MBI molecules in new crystals are protonated and both nitrogen atoms in the cation $(\mathrm{MBI}+\mathrm{H})^{+}$form a valence bond with hydrogen atoms. So, the double carbon-nitrogen valence bonds disappear as well as the corresponding line in the Raman spectra.

In Raman spectra of new crystals there are lines which are characteristic of phosphoric or phosphorous acid. A doublet (No. 4 in Table 2) at 2363 and $2382 \mathrm{~cm}^{-1}$, which presents in the MBI-phosphite spectrum, corresponds to the stretching vibration of the valence bond $\mathrm{P}-\mathrm{H}$, characteristic to phosphites $[5,20,45-47]$. 
In the spectral range from 900 to $1000 \mathrm{~cm}^{-1}$ in Raman spectra of new crystals there are lines (Nos. 23 and 25), which are absent in spectrum of MBI. These lines correspond to the symmetric stretching vibration of the valence bonds in acid molecules in phosphite anion $[5,45,47]$ and phosphate anion [49,52,53]. In the region of lower frequencies, two lines (Nos. 38 and 43) at 515 and $380 \mathrm{~cm}^{-1}$ observed in spectrum of the MBI-phosphate- 1 and the MBI-phosphate- 2 are characteristic to oscillations of the phosphoric acid molecule [53,55]. Line No. 37 at $537 \mathrm{~cm}^{-1}$ in spectrum of the MBI-phosphite, corresponds well to the line observed in $\mathrm{H}_{2} \mathrm{PO}_{3}$ - phosphite anion [5,54]. The line at $1302 \mathrm{~cm}^{-1}$ (No. 15), which manifests itself in both MBI phosphates, may be interpreted as a bending of the hydrogen bond between the tetrahedra of phosphoric acid, similarly to potassium dihydrogenphosphate (KDP) [51]. The lines at $1637 \mathrm{~cm}^{-1}$ and $1515 \mathrm{~cm}^{-1}$ (Nos. 5 and 8), observed in three new crystals, probably correspond to oscillations inside the water molecule [48-50].

Figure 9 demonstrates the polarized Raman spectra of the MBI-phosphite crystal (recorded by T64000 Advanced Research Raman System) in different experimental geometries. Positions of lines are presented in Table 3. The MBI-phosphite belongs to monoclinic syngony, and its Raman spectra show pronounced polarization dependence. Raman spectra of the MBI-phosphite were obtained for $-\mathrm{Z}(\mathrm{XX)Z}, \mathrm{Z}(\mathrm{YY}) \mathrm{Z}$, and $-\mathrm{Z}(\mathrm{XY}) \mathrm{Z}$ backscattering geometries, where $\mathrm{Z}$ is normal to the crystal plane (100), $\mathrm{X}$ is $\mathrm{c}^{*}$-axis, and $\mathrm{Y}$ is b-axis $\left(\mathrm{C}_{2}\right)$.

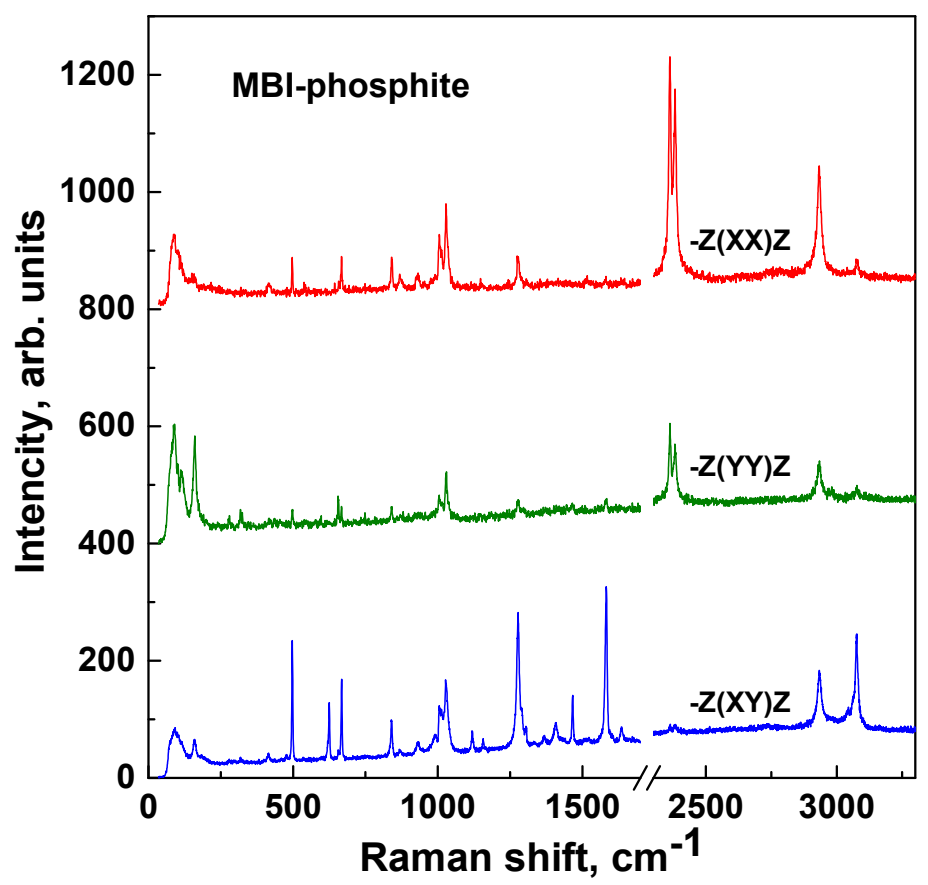

Figure 9. Raman spectra of MBI-phosphite crystal for different experimental geometries.

Table 3. Lines observed in MBI-phosphite polarized Raman spectra. Abbreviations: vs - very strong, sstrong, $\mathrm{m}$ - medium, $\mathrm{w}$ - weak, $\mathrm{b}$ - broad, $\Gamma$ - out-of-plane bending, $\delta$-in-plane bending, $v$ - stretching, $\mathrm{M}$ - methyl group. The vibrational symmetry in assignments is provided in terms of the $\mathrm{C}_{3 \mathrm{v}}$ structure for the internal $\mathrm{HPO}_{3}{ }^{2-}$ vibrations and in terms of the $\mathrm{C}_{\mathrm{s}}$ structure for the internal MBI vibrations.

\begin{tabular}{cccccccc}
\hline $\begin{array}{c}\text { Wavenumber, } \\
\mathbf{c m}^{-\mathbf{1}}\end{array}$ & $-\mathbf{Z}(\mathbf{X X ) Z}$ & $-\mathbf{Z}(\mathbf{Y}) \mathbf{Z}$ & $-\mathbf{Z}(\mathbf{X Y ) Z}$ & Powder & Assignment & Sym. \\
\hline 3076 & $\mathrm{~m}$ & $\mathrm{w}$ & $\mathrm{s}$ & $\mathrm{sb}$ & $\mathrm{MBI}: v_{\mathrm{CH}}\left(A^{\prime}\right)$ & $B_{g}$ \\
\hline 2934 & $\mathrm{~s}$ & $\mathrm{~m}$ & $\mathrm{~s}$ & $\mathrm{~s}$ & $\mathrm{MBI}: \mathrm{M} v_{\mathrm{CH}}\left(A^{\prime \prime}\right)$ & $A_{g}, B_{g}$ \\
\hline 2363 & $\mathrm{vs}$ & $\mathrm{vs}$ & $\mathrm{w}$ & $\mathrm{vs}$ & $\mathrm{H}_{3} \mathrm{PO}_{3}: v_{\mathrm{PH}}\left(A_{1}\right)$ & $A_{g}$ \\
2382 & $\mathrm{vs}$ & $\mathrm{vs}$ & $\mathrm{w}$ & $\mathrm{vs}$ & $\delta_{\mathrm{H} 2 \mathrm{O}}$ & $B_{g}$ \\
\hline 1637 & & & $\mathrm{~m}$ & $\mathrm{w}$ & & \\
\hline
\end{tabular}


Table 3. Cont.

\begin{tabular}{|c|c|c|c|c|c|c|}
\hline $\begin{array}{l}\text { Wavenumber, } \\
\qquad \mathrm{cm}^{-1}\end{array}$ & $-Z(X X) Z$ & $-Z(Y Y) Z$ & $-Z(X Y) Z$ & Powder & Assignment & Sym. \\
\hline 1583 & $\mathrm{w}$ & $\mathrm{mb}$ & vs & & MBI: $v_{\mathrm{CC}}\left(A^{\prime}\right)$ & $B_{g}$ \\
\hline 1517 & $\mathrm{w}$ & & $\mathrm{w}$ & & $\delta_{\mathrm{H} 2 \mathrm{O}}$ & $A_{g}, B_{g}$ \\
\hline 1466 & & & $\mathrm{~s}$ & & MBI: $\delta_{\mathrm{CCH}}+v_{\mathrm{CC}}\left(A^{\prime}\right)$ & $B_{g}$ \\
\hline 1408 & & & $\mathrm{~s}$ & & MBI: $\mathrm{M} \delta_{\mathrm{CH} 2}+\delta_{\mathrm{CCH}}\left(A^{\prime}\right)$ & $B_{g}$ \\
\hline 1369 & & & $\mathrm{~m}$ & & $\begin{array}{c}\text { MBI: } v_{\mathrm{CC}}+v_{\mathrm{CN}}+\mathrm{M} \delta_{\mathrm{CH} 2} \\
\left(A^{\prime}\right)\end{array}$ & $B_{g}$ \\
\hline 1276 & $\mathrm{~m}$ & $\mathrm{w}$ & vs & $\mathrm{s}$ & MBI: $v_{\mathrm{CN}}+v_{\mathrm{CC}}+\delta_{\mathrm{CCH}}\left(A^{\prime}\right)$ & $B_{g}$ \\
\hline 1157 & & & $\mathrm{~m}$ & & MBI: $\delta_{\mathrm{CCH}}\left(A^{\prime}\right)$ & $B_{g}$ \\
\hline 1119 & & & $\mathrm{~m}$ & & MBI: $\delta_{\mathrm{CCH}}+v_{\mathrm{CC}}\left(A^{\prime}\right)$ & $B_{g}$ \\
\hline 1028 & $\mathrm{~s}$ & $\mathrm{~s}$ & $\mathrm{~s}$ & $\mathrm{~s}$ & MBI: $v_{\mathrm{CC}}+v_{\mathrm{CN}}\left(A^{\prime}\right)$ & $A_{g},\left(B_{g}\right)$ \\
\hline 1006 & $\mathrm{~m}$ & $\mathrm{~m}$ & $\mathrm{~s}$ & $\mathrm{~s}$ & MBI: $v_{\mathrm{CC}}+\delta_{\mathrm{CCH}}\left(A^{\prime}\right)$ & $A_{g}, B_{g}$ \\
\hline 991 & & & $\mathrm{~m}$ & & $v_{\mathrm{OPO}}\left(A_{1}\right)$ & $B_{g}$ \\
\hline 930 & $\mathrm{w}$ & & $\mathrm{mb}$ & $\mathrm{sb}$ & $v_{\mathrm{OPO}}\left(A_{1}\right)$ & $B_{g},\left(A_{g}\right)$ \\
\hline 867 & $\mathrm{~m}$ & & $\mathrm{mb}$ & $\mathrm{s}$ & $\begin{array}{c}\text { MBI: } \Gamma_{\mathrm{CCCH}}+\Gamma_{\mathrm{HCCN}}+ \\
\Gamma_{\mathrm{HCCH}}+\Gamma_{\mathrm{CCCH}}\left(A^{\prime \prime}\right)\end{array}$ & $A_{g},\left(B_{g}\right)$ \\
\hline 840 & $\mathrm{~m}$ & $\mathrm{~m}$ & $\mathrm{~s}$ & $\mathrm{~s}$ & MBI: $v_{\mathrm{CC}}\left(A^{\prime}\right)$ & $B_{g},\left(A_{g}\right)$ \\
\hline 745 & $\mathrm{w}$ & $\mathrm{w}$ & & & MBI: $\Gamma_{\mathrm{CCCH}}+\Gamma_{\mathrm{HCCN}}\left(A^{\prime \prime}\right)$ & $A_{g}$ \\
\hline 667 & $\mathrm{~m}$ & $\mathrm{w}$ & $\mathrm{s}$ & $\mathrm{s}$ & $\begin{array}{c}\text { MBI: } v_{\mathrm{CC}}+\delta_{\mathrm{CCC}}+\delta_{\mathrm{CCN}} \\
\left(A^{\prime}\right)\end{array}$ & $B_{g},\left(A_{g}\right)$ \\
\hline 656 & $\mathrm{~m}$ & $\mathrm{~m}$ & $\mathrm{w}$ & $\mathrm{w}$ & $\begin{array}{c}\text { MBI: } \Gamma_{\mathrm{CNCN}}+\Gamma_{\mathrm{HCCN}}+ \\
\Gamma_{\mathrm{CCCN}}+\Gamma_{\mathrm{HNCN}}\left(A^{\prime \prime}\right)\end{array}$ & $A_{g},\left(B_{g}\right)$ \\
\hline 624 & & & $\mathrm{~s}$ & $\mathrm{w}$ & $\begin{array}{c}\text { MBI: } \delta_{\mathrm{CCN}}+\delta_{\mathrm{CCC}}+v_{\mathrm{CC}} \\
\left(A^{\prime}\right)\end{array}$ & $B_{g}$ \\
\hline 537 & $\mathrm{~m}$ & & & $\mathrm{w}$ & $\begin{array}{c}\mathrm{H}_{3} \mathrm{PO}_{3} \text { : } \\
\mathrm{HPO}_{3} \text { asym. bending }(E)\end{array}$ & $A_{g}$ \\
\hline 497 & $\mathrm{~m}$ & $\mathrm{~m}$ & vs & $\mathrm{s}$ & MBI: $\delta_{\mathrm{CCC}}+v_{\mathrm{CC}}+v_{\mathrm{CN}}\left(A^{\prime}\right)$ & $B_{g},\left(A_{g}\right)$ \\
\hline 415 & $\mathrm{mb}$ & & $\mathrm{m}$ & $\mathrm{m}$ & $\begin{array}{l}\text { lattice modes? Water } \\
\text { libration? } \Gamma_{\mathrm{CCNH}}\end{array}$ & $A_{g},\left(B_{g}\right)$ \\
\hline 318 & & $\mathrm{~m}$ & $\mathrm{~m}$ & & MBI: $\Gamma_{\mathrm{CCCN}}+\Gamma_{\mathrm{CCNH}}\left(A^{\prime \prime}\right)$ & $A_{g},\left(B_{g}\right)$ \\
\hline 279 & & $\mathrm{w}$ & $\mathrm{w}$ & & MBI: $\delta_{\mathrm{CCN}}\left(A^{\prime}\right)$ & $A_{g},\left(B_{g}\right)$ \\
\hline 160 & $\mathrm{mb}$ & $\mathrm{s}$ & $\mathrm{s}$ & $\mathrm{s}$ & MBI: $\Gamma_{\mathrm{CCCN}}+\Gamma_{\mathrm{HCCN}}\left(A^{\prime \prime}\right)$ & $A_{g},\left(B_{g}\right)$ \\
\hline 89 & $\mathrm{sb}$ & $\mathrm{sb}$ & $\mathrm{sb}$ & $\mathrm{sb}$ & $\begin{array}{l}\text { MBI: } \Gamma_{\mathrm{HCCN}}\left(A^{\prime \prime}\right) ? \\
\text { lattice mode? }\end{array}$ & $A_{g},\left(B_{g}\right)$ \\
\hline
\end{tabular}

The unit cell of the MBI-phosphite consists of 212 atoms; that gives $3 * 212-3=633$ external and internal optic phonon modes. They are distributed according to irreducible representations as follows: $159 \mathrm{Ag}+159 \mathrm{Bg}+158 \mathrm{Au}+157 \mathrm{Bu}$. For P2 1 /ccrystal symmetry, there are two irreducible representations, $\mathrm{Ag}$ and $\mathrm{Bg}$ for Raman active modes, which Raman tensors have the following form [57]:

$$
\mathrm{Ag}=\left(\begin{array}{lll}
a & d & 0 \\
d & b & 0 \\
0 & 0 & c
\end{array}\right)
$$




$$
\mathrm{Bg}=\left(\begin{array}{lll}
0 & 0 & e \\
0 & 0 & f \\
e & f & 0
\end{array}\right)
$$

These tensors are written for a set of crystal axes ( $x, y$, and $z)$, chosen such that the crystallographic axis of the $\mathrm{C}_{2}$ point group (b-axis) is along the $\mathrm{z}$ direction and the $x y$ plane is perpendicular to the $\mathrm{z}$-axis. Selection rules for experimental geometries used in our study, written in laboratory coordinate system $\mathrm{X}, \mathrm{Y}, \mathrm{Z}$, are given in Table 4. Also, Table 4 presents the number of acoustic, translational, librational, and internal modes related to $\mathrm{Ag}, \mathrm{Bg}, \mathrm{Au}$, and $\mathrm{Bu}$ irreproducible representations. Note that in the crystal structure there are $\mathrm{H}_{2} \mathrm{PO}_{3}{ }^{-}$anions interconnected by the hydrogen bonds formed by one of two protons of $\mathrm{H}_{2} \mathrm{PO}_{3}{ }^{-}$anion. In Table 4 we consider separately the internal modes of tetrahedrons $\mathrm{HPO}_{3}{ }^{2-}$ and oscillations of protons in the hydrogen bonds.

Table 4. Results of the factor group analysis for the MBI-phosphite crystal vibrations and selection rules for $\mathrm{Ag}$ and $\mathrm{Bg}$ Raman active modes. Space group P2 $1 / \mathrm{C}(\mathrm{Z}=4)$. Abbreviations: $\mathrm{N}=$ total number of modes, $\mathrm{A}=$ acoustic, $\mathrm{T}=$ translational, $\mathrm{L}=$ librational, $\mathrm{i}=$ inactive. Selection rules are given for backscattering geometries $-\mathrm{Z}(\mathrm{XX}) \mathrm{Z},-\mathrm{Z}(\mathrm{YY}) \mathrm{Z},-\mathrm{Z}(\mathrm{XY}) \mathrm{Z}$.

\begin{tabular}{|c|c|c|c|c|c|c|c|c|c|}
\hline \multirow{2}{*}{$C_{2 \mathrm{~h}}$} & \multirow{2}{*}{$N$} & \multirow{2}{*}{$A$} & \multirow{2}{*}{$T$} & \multirow{2}{*}{$L$} & \multicolumn{3}{|c|}{ Internal Modes } & \multirow{2}{*}{$\begin{array}{c}\text { Hydrogen Bonds } \\
\text { between } \mathrm{HPO}_{3}{ }^{2-} \\
\text { Vibrations }\end{array}$} & \multirow{2}{*}{$\begin{array}{c}\text { Selection } \\
\text { Rules }\end{array}$} \\
\hline & & & & & $(\mathrm{MBI}+\mathrm{H})^{+}$ & $\mathrm{HPO}_{3}{ }^{2-}$ & $\mathrm{H}_{2} \mathrm{O}$ & & \\
\hline$A_{g}$ & 159 & 0 & 15 & 15 & 102 & 18 & 3 & 6 & $X X, Y Y$ \\
\hline$B_{g}$ & 159 & 0 & 15 & 15 & 102 & 18 & 3 & 6 & $X Y$ \\
\hline$A_{u}$ & 159 & 1 & 14 & 15 & 102 & 18 & 3 & 6 & $\mathrm{i}$ \\
\hline$B_{u}$ & 159 & 2 & 13 & 15 & 102 & 18 & 3 & 6 & $\mathrm{i}$ \\
\hline
\end{tabular}

Classification of lines (Ag or Bg) observed in Raman spectra of MBI-phosphite (Figure 9) is presented in Table 3. Also, in the last column of Table 3 for lines, which are present in MBI and MBI-phosphite spectra, classification $\left(\mathrm{A}^{\prime}\right.$ or $\left.\mathrm{A}^{\prime \prime}\right)$ is given. Note that most of the MBI molecule oscillations related to in-plane deformation $\left(\mathrm{A}^{\prime}\right)$ correspond to Bg modes in MBI-phosphite crystal. In experimental Raman spectra we observe lines active in $X X$ and $Y Y$ geometries, but inactive in $X Y$ geometry $(\mathrm{Ag})$, and lines active in $X Y$ geometry, but passive in $X X$ and $Y Y$ geometries $(\mathrm{Bg})$. Some lines apart from strong components allowed in Ag or Bg mode have a small admixture of Bg or Ag. Such lines are marked as $\mathrm{Ag}(\mathrm{Bg})$ or $\mathrm{Bg}(\mathrm{Ag})$.

Two strong lines at 2363 and $2382 \mathrm{~cm}^{-1}$, which are observed in $X X$ and $Y Y$ polarizations but not in $X Y$ polarization, correspond to phosphite-anione's fundamental mode $v 1$ (Ag) caused by the stretching of a P-H valence bond [5,20,45-47]. The presence of two lines indicates the existence of two nonequivalent positions occupied by the phosphorous acid tetrahedron $\mathrm{HPO}_{3}{ }^{2-}$ in the MBI-phosphite crystal that is confirmed by crystal XRD analysis. Note that the intensity of these lines in XX polarization is approximately two times stronger than in $Y Y$ polarization. This may be due to the fact that the $\mathrm{P}-\mathrm{H}$ bond is closer to the $c^{*}$-axis than to the b-axis.

Concluding this section, we note, that the analysis of Raman spectra of new crystals confirms the results of XRD studies. In Raman spectra of new crystals there are lines related to vibrations of MBI or corresponding acids and water molecules.

\subsection{Dielectric Measurements}

\subsubsection{MBI-Phosphite}

Small signal dielectric response ( $\varepsilon$ and $\operatorname{tg} \delta$ ) in the MBI-phosphite single crystals along a, b, $c^{*}$ crystal axes reveals considerable anisotropy. Below room temperature, no dielectric anomalies was observed. The values of dielectric constant $\varepsilon_{\mathrm{a}}=18, \varepsilon_{\mathrm{b}}=\varepsilon_{\mathrm{c}^{*}}=3$ only slightly depend upon frequency 
and the dielectric losses are small $(\operatorname{tg} \delta \sim 0.01-0.02)$. Maximal value of the dielectric constant is observed along the a-axis, i.e., along zig-zag chains of hydrogen bonds type $\mathrm{N}$... H-O and $\mathrm{O}$... H-O between the MBI molecules and the $\mathrm{HPO}_{3}$ tetrahedra in the crystal structure (see Figure 3b).

Figure 10 presents the temperature dependence of dielectric constant $\varepsilon_{\mathrm{a}}$ and dielectric losses $\operatorname{tg} \delta$ along [100] direction in MBI-phosphite at different frequencies. With heating above $250 \mathrm{~K}$, a strong increase and a low frequency dispersion of $\varepsilon_{\mathrm{a}}$ and $\operatorname{tg} \delta$ was observed.
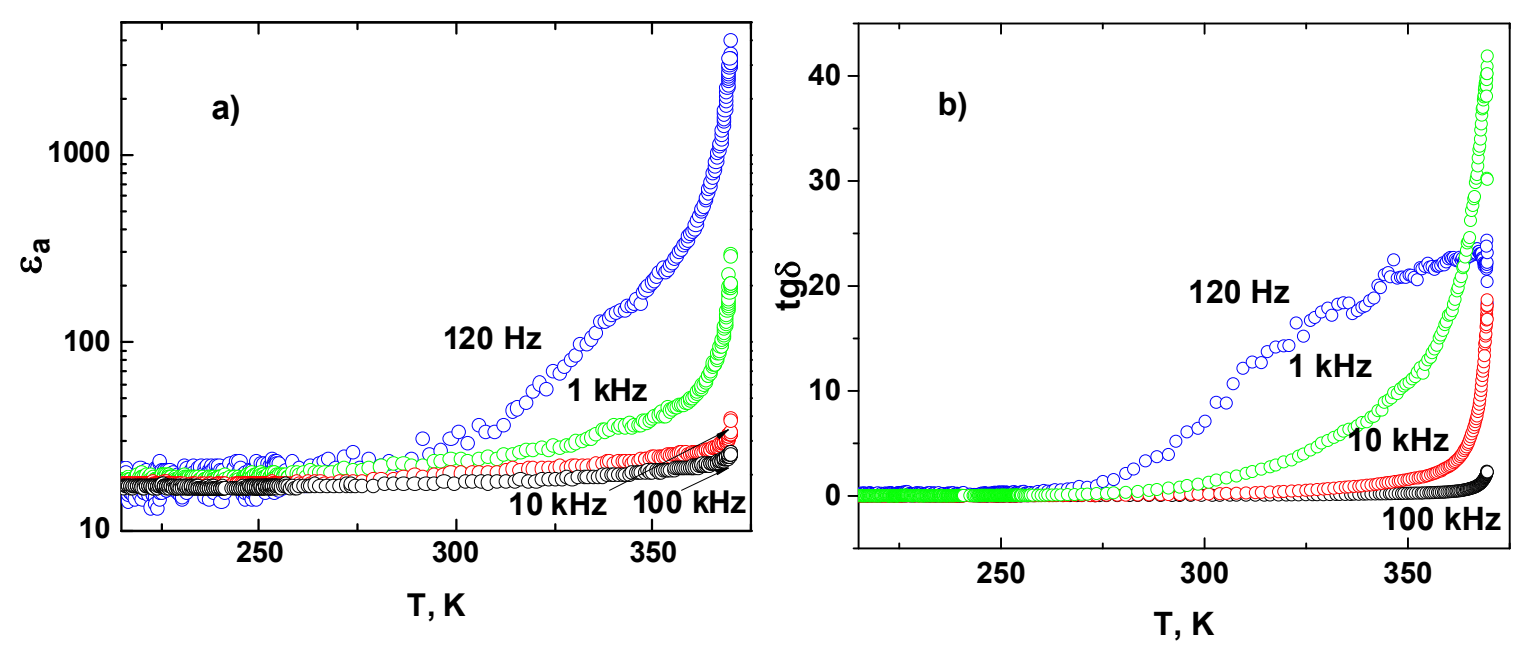

Figure 10. Temperature dependence of dielectric constant $\varepsilon_{\mathrm{a}}$ (in semi-logarithmic scale) (a) and $\operatorname{tg} \delta$ (b) in MBI-phosphite crystal along the a-axis for different frequencies $\mathrm{f}$.

Such temperature behavior is characteristic for ionic (protonic) conductivity in crystals with hydrogen bonds $[23,58,59]$. Specific electric conductivity is calculated as $\sigma=\omega \varepsilon_{0} \varepsilon^{\prime} \operatorname{tg} \delta=\omega \varepsilon_{0} \varepsilon^{\prime \prime}$, where $\omega=2 \pi f$ the angular frequency. Figure 11a shows the MBI-phosphite-specific conductivity $\sigma$ as a function of inverse temperature for $a-, b-$, and $c^{*}$-axes in a semilogarithmic scale. In just-prepared crystal at heating above $250 \mathrm{~K}$ up to $330 \mathrm{~K}$, the conductivity $\sigma_{\mathrm{a}}$ along the a-axis did not reveal frequency dispersion in the frequency range $120-1 \mathrm{k} \mathrm{Hz}$ that indicates manifestation of direct current (DC) conductivity. In this temperature range and in this direction, the increase of DC conductivity is described by Arrhenius law:

$$
\sigma(T)=\sigma_{0} e^{-\frac{E_{a}}{k T}}
$$

where $\mathrm{E}_{\mathrm{a}}=0.46 \mathrm{eV}$ is the activation energy and $\sigma_{0}=140 \mathrm{Sm}^{-1}$ the preexponential factor. The value of conductivity along the $b$ - and $c^{*}$-axes is much smaller, comparable with the level of experimental errors, up to the temperature $\mathrm{T}=330 \mathrm{~K}$.

The annealing of the MBI-phosphite at a higher temperature results in the conductivity increase by several orders of magnitude. Above $330 \mathrm{~K}$ the conductivity strongly increases along all axes and the crystal transforms into a "conducting state", in which it remains upon subsequent cooling to room temperature. Figure $11 \mathrm{~b}$ shows frequency dependence of conductivity along the $\mathrm{b}$ - and $\mathrm{c}^{*}$-axes at high temperature in the MBI-phosphite. In the frequency range $10^{3}-5 \cdot \times 10^{4} \mathrm{~Hz}$ the conductivity is approximately constant. That indicates DC conductivity $\sigma_{\mathrm{dc}}$. The decrease of conductivity at low frequencies below $10^{3} \mathrm{~Hz}$ is caused by the electrode polarization effect characteristic for ionic conductivity $[60,61]$. The increase of conductivity above $10^{4}$ indicated manifestation of hopping mechanism [61]. The only candidates for the role of charge carriers are the protons. Note that the proton conductivity has been observed in a large number of crystals with hydrogen bonds such as DBPI-DBP [23,58], MBI [59,62], etc.

The magnitude of DC conductivity decreased with cooling in accordance to Arrhenius law with isotropic activation energy $E_{a}=0.6 \mathrm{eV}$. This value of $E_{a}$ is smaller than for protonic conductivity in ferroelectrics with hydrogen bonds, where $\mathrm{E}_{\mathrm{a}} \approx 0.8-1 \mathrm{eV}[23,58,59]$, but is close to the value of activation 
energy of conductivity in proton superionics [63]. Note that both the sharp increase in conductivity above a certain temperature and the value of activation energy of conductivity is characteristic of proton superionics [63].
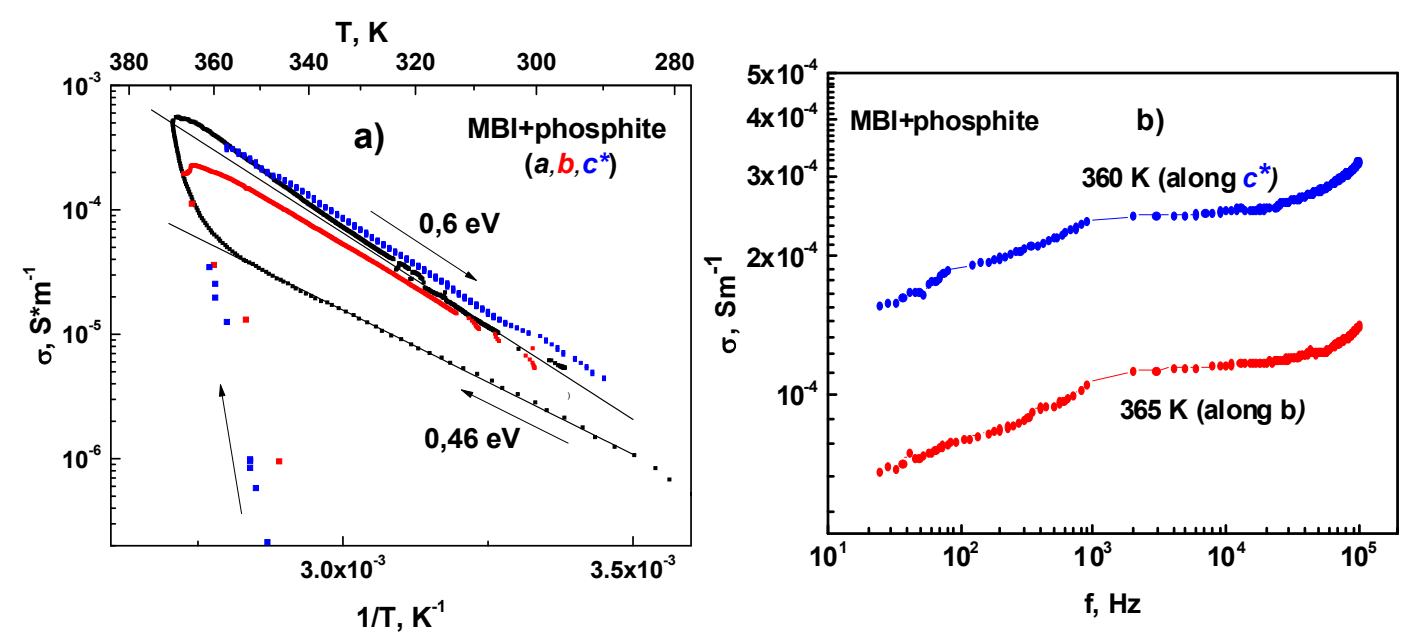

Figure 11. (a) Specific conductivity of MBI-phosphite for a-, b-, and $c^{*}$-axes in semilogarithmic scale as a function of inversed temperature. Lines correspond to Arrhenius law approximation for heating and cooling. (b) Frequency dependence of conductivity (log-log plot) along the a- and b-axes at high temperature in MBI-phosphite.

Because the annealing of the MBI-phosphite transforms it into a "conducting state", a thermal cycling of the crystals was performed with increasing maximum temperature $\mathrm{T}_{\max }$. The increase of conductivity at temperatures above $350 \mathrm{~K}$ occurred even at a constant temperature with time. This means that the preexponential factor $\sigma_{0}$ in the Arrhenius law (Equation (3)) depends on both the temperature $\mathrm{T}$ and duration of annealing $\mathrm{t}$.

Figure 12 shows the temperature dependence of preexponential factor $\sigma_{0}$ for several heating-cooling circles. The speed of temperature change was $\mathrm{dT} / \mathrm{dt} \sim 1 \mathrm{~K} / \mathrm{min}$. The first circle corresponds to the temperature increase up to $353 \mathrm{~K}$ and consequent cooling to $315 \mathrm{~K}$. The value of $\sigma_{0}$ reaches $\sim 7^{*} 10^{2} \mathrm{Sm}^{-1}$ and remains constant at cooling. The second circle was started after keeping the crystal at room temperature for 18 hours. During this circle the temperature was increased up to $360 \mathrm{~K}$, stopped for $30 \mathrm{~min}$, and then decreased to $295 \mathrm{~K}$. We clearly see that the process of defect generation successfully goes at constant temperature. The value of $\sigma_{0}$ was increased up to $3 \times 10^{4} \mathrm{Sm}^{-1}$ and was not changed under cooling. Keeping the sample at room temperature for 2 days was followed by some decrease of conductivity, but the following temperature increased up to $325 \mathrm{~K}$ resulted in recovery of a preexponential factor up to $3 \times 10^{4} \mathrm{Sm}^{-1}$. Analogous recovery was observed in the conductivity circle 4 . The preexponential factor $\sigma_{0}$ increased with the temperature $\mathrm{T}_{\max }$ increase during the thermal cycling. At cooling the conductivity followed well to Arrhenius law with constant preexponential factor $\sigma_{0}$ (see Figure 11a). The activation energy of conductivity $E_{a}$ at cooling in all crystallographic directions was always equal to $0.6 \mathrm{eV}$. We can suppose that the annealing of crystal at temperatures above $350 \mathrm{~K}$ resulted in generation of defects, which contributed to the conductivity. The preexponential factor $\sigma_{0}$ in the Arrhenius law in this case should be proportional to concentration $\mathrm{n}$ of thermoactivated defects.

So, the temperature increase above $350 \mathrm{~K}$ was followed by the appearance of defects, which contributed to the conductivity. Defects concentration was approximately constant at cooling but decreased with keeping the sample at room temperature for several days. It is remarkable that the temperature increase up to relatively low temperature $325 \mathrm{~K}$ resulted in recovery of the defect concentration $\mathrm{n}$ up to the value reached during the previous heating-cooling circle (memory effect). It appears that while keeping a crystal at room temperature, some of defects transformed to the state in which they do not contribute to total conductivity, and for their recovery to the "conducting state" the 
heating up to temperature $325 \mathrm{~K}$ is needed. The possibility to manipulate by conductivity in large limits may be attractive for some applications, for example, for preparing membranes for fuel elements.

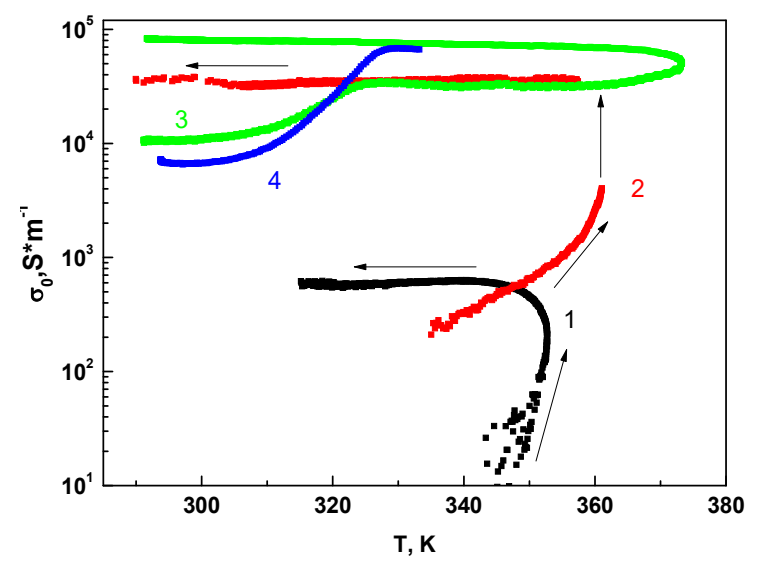

Figure 12. Temperature dependence of preexponential factor $\sigma_{0}$ for four heating-cooling circles of MBI-phosphite.

\subsubsection{MBI-Phosphate-2}

Figure 13 presents frequency dependence of conductivity in the MBI-phosphate-2 along [011] direction for temperatures $\mathrm{T}=293$ calculated from dielectric data. Frequency dependence of the conductivity (Figure 13) obeyed the well-known general formula [60] $\sigma=\sigma_{\mathrm{dc}}+A \omega^{\mathrm{s}}$ with temperature-dependent parameters $\mathrm{A}$ and $\mathrm{s}(\mathrm{s} \leq 1)$. A rough estimation of parameters from our experiments showed that the magnitude of $s$ in the studied temperature range was in the limits from 0.3 to 1 that is in agreement with theory. $\mathrm{Up}$ to $\mathrm{f}=10 \mathrm{kHz}$ the conductivity did not depend on frequency that evidence the direct current conductivity. The Cole-Cole plot for complex resistivity $\left(\rho^{*}=1 /\left[\mathrm{i} \varepsilon_{0} \omega\left(\varepsilon^{\prime}\right.\right.\right.$ $\left.\left.-i \varepsilon^{\prime \prime}\right)\right]$ is presented in the inset of Figure 13. The Cole-Cole plot showed very good half circle that indicates on an Ohmic contacts in the sample and gives the value of DC resistivity for the sample at different temperature. In the MBI-phosphate- 2 crystal at room temperature (293 K), the value of specific conductivity along [011] axis is about $\sigma=4 \times 10^{-5} \mathrm{Sm}^{-1}$. Temperature increase up to $329 \mathrm{~K}$ was followed by the increase of the conductivity to $\sigma=5 \times 10^{-4} \mathrm{Sm}^{-1}$. The cooling up to $200 \mathrm{~K}$ resulted in the conductivity decrease to values of $\sim 10^{-8} \mathrm{Sm}^{-1}$.

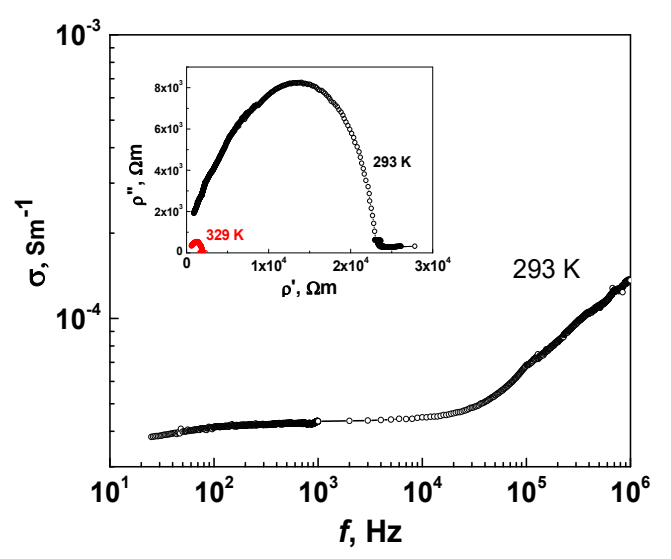

Figure 13. Frequency dependence of specific conductivity along [011] in MBI-phosphate-2 at temperatures of $\mathrm{T}=293$ and $329 \mathrm{~K}$. Inset shows Cole-Cole plot of complex resistivity.

Figure 14 reveals the temperature dependence of a real and imaginary part of dielectric constant of the MBI-phosphate-2 crystal at low temperatures along [011] crystal axis. The real part of the dielectric constant is relatively large, $\varepsilon^{\prime} \approx 23$, and is increased with cooling. The imaginary part $\varepsilon^{\prime \prime}$ 
is approximately two orders of magnitude smaller and does not reveal considerable temperature dependence. Such behavior of $\varepsilon(T)$ is similar to quantum paraelectrics and can be described by the Barrett formula [64]:

$$
\varepsilon=\varepsilon_{b g}+\frac{C_{C W}}{\frac{T_{1}}{2} \operatorname{coth}\left(\frac{T_{1}}{2 T}\right)-T_{0}}
$$

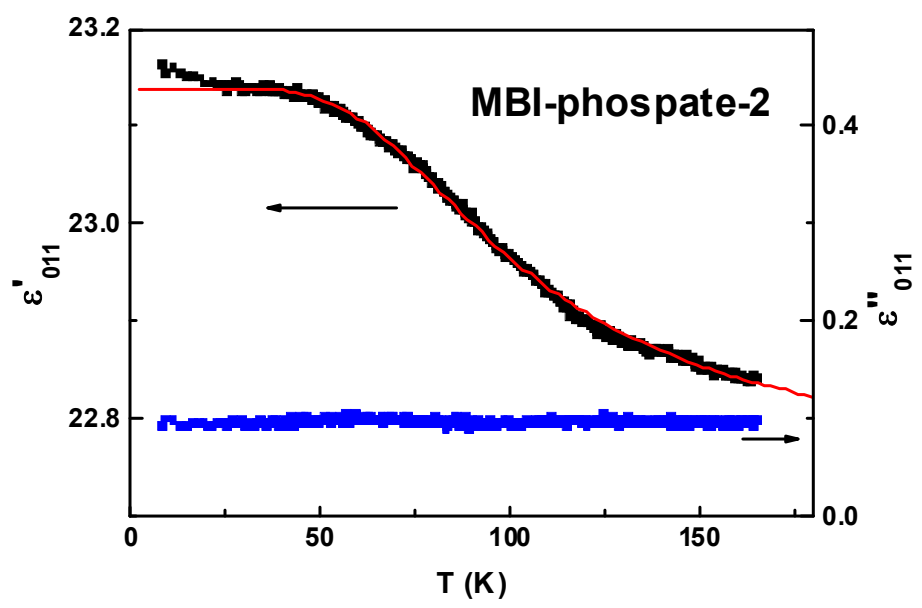

Figure 14. Temperature dependence of real and imaginary parts of dielectric constant at $\mathrm{f}=10 \mathrm{kHz}$ in MBI-phosphate-2. Line shows fitting using Barrett formula.

Parameters obtained by best fitting the experimental $\varepsilon^{\prime}(T)$ dependence by Equation (4) are as follows: $T_{1}=326 \mathrm{~K}, T_{0}=146 \mathrm{~K}$, Curie-Weiss constant $C_{C W}=6.8 \mathrm{~K}$, phone dielectric constant $\varepsilon_{b g}=22.7$. In quantum paraelectrics the Curie-Weiss constant usually is larger and $T_{1}$ considerably smaller. In particular, in rutile $\mathrm{TiO}_{2} T_{1}=135 \mathrm{~K}, \mathrm{C}_{\mathrm{CW}}=39500 \mathrm{~K}$ [65]. Note that quantum paraelectric behavior has been observed also in organic and semiorganic materials $[14-16,66]$. In semiorganic molecular crystal tetrathiafulvalene+halogen-substituted quinone $\left(\mathrm{TTF}+\mathrm{QBr}_{2} \mathrm{I}_{2}\right) T_{1}=71 \mathrm{~K}, \mathrm{C}_{\mathrm{CW}}=6300 \mathrm{~K}[16]$. A small value of Curie-Weiss constant in MBI-phosphate-2 reflects weakness of dielectric anomaly. Note that analogous relatively small increase of dielectric constant has been observed in [16]. The large value of $T_{1}$ can be explained by the fact that MBI-phosphate-2 consists of light atoms. In the single-ion microscopic model, $T_{1}$ is inversely proportional to the square root of the ion mass [64].

Anomalous dielectric behavior in the MBI-phosphate-2 was observed in direction of [011] type which is oriented at $45^{\circ}$ to the chains of the MBI molecules and phosphoric tetrahedrons connected by hydrogen bonds (see Figure $5 \mathrm{c}$ ). High values of dielectric constant were also observed along similar chains in MBI-phosphite crystals (Figure 3b). This means that there was some polar mode responsible for the high value of dielectric constant at room temperature and the increase of dielectric constant at temperature decrease. Also, this mode may be suppressed by quantum fluctuations at low temperature.

\section{Conclusions}

Three new crystals based on 2-methylbenzimidazole and inorganic phosphorous or phosphoric acids were grown by evaporation method. X-ray measurements of single crystals and powders showed that the crystal structure of the MBI-phosphite $\left(\left(\mathrm{C}_{8} \mathrm{H}_{9} \mathrm{~N}_{2}\right)_{2}{ }^{*}\left(\mathrm{PO}_{3} \mathrm{H}_{2}\right)_{2}{ }^{*} \mathrm{H}_{2} \mathrm{O}\right)$ belonged to centrosymmetric space group $\mathrm{P} 2_{1} / \mathrm{c}$ of monoclinic syngony. Crystals of the MBI-phosphate- 1 and the MBI-phosphate- 2 belonged to centrosymmetric space group $P \overline{1}$ of triclinic syngony. Crystal structures of these substances were formed by the cations $(\mathrm{MBI}+\mathrm{H})^{+}$, anions $\mathrm{H}_{2} \mathrm{PO}_{3}{ }^{-}$or $\mathrm{H}_{2} \mathrm{PO}_{4}^{-}$, and water molecules. The appearance of the cations and anions was due to the protonation process, in which the MBI molecule attracted proton from acid molecules. Flat $(\mathrm{MBI}+\mathrm{H})^{+}$cations formed a layered structure connected by $2 \mathrm{D}^{-}$or $3 \mathrm{D}^{-}$net of hydrogen bonds. The protonation resulted in the absence of 
$\mathrm{N}$... H-N hydrogen bonds between the MBI molecules, which were present in MBI crystals and were responsible for ferroelectricity of this material.

Raman spectra of new crystals consisted of lines corresponding to internal vibration of the MBI, acids, and water molecules, and confirm the results of XRD analysis, in particular, the absence of double carbon-nitrogen valence bonds. Polarization of lines measured in different experimental geometries was in accordance with the symmetry obtained by XRD.

As shown dielectric measurements of the MBI-phosphite and MBI-phosphate-2, the dielectric constant in direction of $\mathrm{N}-\mathrm{H} \ldots \mathrm{O}$ and $\mathrm{O}-\mathrm{H}$... O hydrogen bonds, which connected the MBI molecules and inorganic acid tetrahedra, had relatively high value $\varepsilon \sim 20$. The heating of the new crystals resulted in considerable (several orders of magnitude) increase of the conductivity and low frequency dispersion of real and imaginary parts of the dielectric constant, characteristic to proton superionics. Similar phenomena were observed in ferroelectric crystals with hydrogen bonds at high temperature.

The value of conductivity depended on temperature and time of annealing. A possible explanation for such behavior suggested that temperature increase above $350 \mathrm{~K}$ resulted in generation of defects, which produced the DC conductivity. Following cooling, the concentration of defects remained constant and conductivity is described by Arrhenius law with activation energy $0.6 \mathrm{eV}$.

At low temperatures, MBI-phosphate-2 manifested properties analogous to quantum paraelectrics. Anizotropy of dielectric constant in the crystals allowed one to propose the existence of polar mode, which frequency can be stabilized by quantum fluctuations at low frequencies.

Supplementary Materials: Table S1. Results of refinement of the MBI-phosphate-1 structure (space group P $\overline{1}$ (N 2)) using single crystal XRD data. Atomic numbers $\mathrm{Z}$, relative coordinates of atoms $(\mathrm{x} / \mathrm{a}, \mathrm{y} / \mathrm{b}, \mathrm{z} / \mathrm{c})$ and their isotropic temperature factors $U$ are shown. Table S2. Atomic displacement parameters for the MBI-phosphate-1( $\mathrm{A} 2)$. Table S3. Bond lengths $(\AA)$ in MBI-phosphate- 1 structure according to results of structure refinement using single crystal XRD data (Table S1). Table S4. Bond angles $\left({ }^{\circ}\right)$ in MBI-phosphate- 1 structure according to results of structure refinement using single crystal XRD data (Table S1). Table S5. Hydrogen-bond geometry $\left(\AA^{\circ},{ }^{\circ}\right)$ in MBI-phosphate- 1 structure according to results of structure refinement using single crystal XRD data (Table S1). Table S6. Results of refinement of the MBI-phosphate-2 structure (space group $\bar{P}(\mathrm{~N} 2)$ ) using single crystal XRD data. Atomic numbers $Z$, relative coordinates of atoms $(x / a, y / b, z / c)$ and their isotropic temperature factors $U$ are shown. Table S7. Atomic displacement parameters for the MBI-phosphate-2 (̊2). Table S8. Bond lengths ( $\mathrm{A})$ in MBI-phosphate-2 structure according to results of structure refinement using single crystal XRD data (Table S6). Table S9. Bond angles $\left({ }^{\circ}\right)$ in MBI-phosphate-2 structure according to results of structure refinement using single crystal XRD data (Table S6). Table S10. Hydrogen-bond geometry $\left(\AA{ }^{\circ},{ }^{\circ}\right.$ in MBI-phosphate-2 structure according to results of structure refinement using single crystal XRD data (Table S6). Table S11. Results of refinement of the MBI-phosphite structure (space group P21/c (N14)) using single crystal and powder XRD data. Atomic numbers $\mathrm{Z}$, relative coordinates of atoms $(\mathrm{x} / \mathrm{a}, \mathrm{y} / \mathrm{b}, \mathrm{z} / \mathrm{c})$ and their isotropic temperature factors $\mathrm{U}$ are shown. Table S12. Atomic displacement parameters for the MBI-phosphite( $\AA 2$ ). Table S13. Selected distances in MBI-phosphite structure according to results of structure refinement, using single crystal and powder XRD data (Table S11). Table S14. Bond angles $\left(^{\circ}\right)$ in MBI-phosphitestructure according to results of structure refinement using single crystal XRD data (Table S11). Table S15. Hydrogen-bond geometry $\left(\AA_{,}^{\circ}\right)$ in MBI-phosphitestructure according to results of structure refinement using single crystal XRD data (Table S11). Table S16. Unit cell parameters obtained by means of intermediate (Le Bail method) and final (Rietveld technique) refinement of MBI-phosphate-1 and MBI-phosphite, using the powder XRD data, and reached agreement factors. Results from single crystal investigations are shown for comparison. Table S17. Bond lengths and angles of MBI molecule in crystals with and without protonation. Figure S1. Structure of cation (MBI+H)+. Atom numbering correspond to Table S17. Table S18. Experimental and calculated elemental composition of the new crystals.

Author Contributions: Formal analysis, Elena Balashova, Fedor Svinarev, Andrey Zolotarev, Aleksandr Levin, and Boris Krichevtsov; Investigation, Elena Balashova, Fedor Svinarev, Andrey Zolotarev, Aleksandr Levin, Pavel Brunkov, Valery Davydov, Alexander Smirnov, Alexey Redkov, and Galina Pankova; Writing - original draft, Elena Balashova, Fedor Svinarev, Andrey Zolotarev, Aleksandr Levin, and Boris Krichevtsov; Writing - review and editing, Elena Balashova, Fedor Svinarev, and Boris Krichevtsov.

Funding: This research was supported within the State Assignments to the Ioffe Institute (0040-2019-0031)

Acknowledgments: The work was carried out with use of the equipment and software of the Joint Research Center "Materials science and characterization in advanced technology" (A. F. Ioffe Physical-Technical Institute of Russian Academy of Sciences).

Conflicts of Interest: The authors declare no conflict of interest. 


\section{References}

1. Horiuchi, S.; Tokura, J. Organic ferroelectrics. Nat. Mater. 2008, 7, 357-366. [CrossRef] [PubMed]

2. Li, J.; Liu, Y.; Zhang, Y.; Cai, H.-L.; Xiong, R.-G. Molecular ferroelectrics: Where electronics meet biology. Phys. Chem. Chem. Phys. 2013, 15, 20786-20796. [CrossRef] [PubMed]

3. Tayi, A.S.; Kaeser, A.; Matsumoto, M.; Aida, T.; Stupp, S.I. Supramolecular ferroelectrics. Nat. Chem. 2015, 7, 281-294. [CrossRef] [PubMed]

4. Sun, Z.; Luo, J.; Zhang, S.H.; Ji, C.H.; Zhou, L.; Li, S.H.; Deng, F.; Hong, M. Solid-State Reversible Quadratic Nonlinear Optical Molecular Switch with an Exceptionally Large Contrast. Adv. Mater. 2013, 25, 4159-4163. [CrossRef]

5. Ghazaryan, V.V.; Zakharov, B.A.; Petrosyan, A.M.; Boldyreva, E.V. L-Argininiumphosphite-A new candidate for NLO materials. Acta Cryst. 2015, C71, 415-421. [CrossRef]

6. Haile, S.M.; Boysen, D.A.; Chisholm, C.R.I.; Merle, R.B. Solid acids as fuel cell electrolytes. Nature 2001, 410, 910-913. [CrossRef]

7. Blazcues-Kastro, A.; Garcia-Kabanes, A.; Carracosa, M. Biological applications of ferroelectric materials. Appl. Phys. Rev. 2018, 5, 041101. [CrossRef]

8. Horiuchi, S.; Kobayashi, K.; Kumai, R.; Ishibashi, S.H. Proton tautomerism for strong polarization switching. Nat. Comm. 2017, 8, 14426. Available online: www.nature.com/naturecommunications (accessed on 16 February 2017). [CrossRef]

9. Chen, S.H.; Zeng, X.C. Design of ferroelectric organic molecular crystals with ultrahigh polarization. J. Am. Chem. Soc. 2014, 136, 6428-6436. [CrossRef]

10. Samara, G.A.; Semmingsen, D. Effects of pressure on the dielectric properties and phase transitions of the 2-D antiferroelectric squaric acid $\left(\mathrm{H}_{2} \mathrm{C}_{4} \mathrm{O}_{4}\right.$ and $\left.\mathrm{D}_{2} \mathrm{C}_{4} \mathrm{O}_{4}\right)$. J. Chem. Phys. 1979, 71, 1401-1407. [CrossRef]

11. Albers, J. Betaine compounds - a new family with ferroelectric and uncommensurate phases. Ferroelectrics 1988, 78, 3-10. [CrossRef]

12. Horiuchi, S.; Tokunaga, Y.; Giovannetti, G.; Picozzi, S.; Itoh, H.; Shimano, R.; Kumai, R.; Tokura, Y. Above-room-temperature ferroelectricity in a single-component molecular crystal. Nature 2010, 463, 789-793. [CrossRef] [PubMed]

13. Kagawa, F.; Hatahara, K.; Horiuchi, S.; Tokura, Y. Domain-wall dynamics coupled to proton motion in a hydrogen-bonded organic ferroelectric. Phys. Rev. B 2012, 85, 220101(R). [CrossRef]

14. Mochida, T.; Izuoka, A.; Sugawara, T. Organic hydrogen-bonded dielectrics: Quantum paraelectricity based on tautomerization of 9-hydroxyphenalenone derivatives. J. Chem. Phys. 1994, 101, 7971-7974. [CrossRef]

15. Takasu, I.; Izuoka, A.; Sugawara, T.; Mochida, T. Observation of Quantum paraelectricity in an intermolecular ionic hydrogen-bonded crystal of a squaric acid derivative. J. Phys. Chem. B 2004, 108, 5527-5531. [CrossRef]

16. Horiuchi, S.; Kobayashi, K.; Kumai, R.; Minami, N.; Kagawa, F.; Tokura, Y. Quantum ferroelectricity in charge-transfer complex crystals. Nat. Comm. 2015, 6, 7469. [CrossRef]

17. Saripalli, R.K.; Swain, D.; Prasad, S.; Nhalil, H.; Bhat, H.L.; Guru Row, T.N.; Elizabeth, S. Observation of ferroelectric phase and large spontaneous electric polarization in organic salt of diisopropylammonium iodide. J. Appl. Phys. 2017, 121, 114101. [CrossRef]

18. Horiuchi, S.; Kagawa, F.; Hatahara, K.; Kobayashi, K.; Kumai, R.; Murakami, Y.; Tokura, Y. Above-roomtemperature ferroelectricity and antiferroelectricity in benzimidazoles. Nat. Comm. 2012, 3, 1308. [CrossRef]

19. Horiuchi, S.; Ishibashi, S.H.; Inada, S.; Aoyagi, S.H. Hydrogen-Bonded Architectures and Field-Induced Polarization Switching in Bridged Bis(benzimidazole) Crystals. Cryst. Growth Des. 2019, 19, 328-335. [CrossRef]

20. Baran, J.; Bator, G.; Jakubas, R.; Sledz, M. Dielectric dispersion and vibrational studies of a new ferroelectric, glyciniumphosphite crystal. J. Phys. Condens. Matter 1996, 8, 10647-10658. [CrossRef]

21. Balashova, E.V.; Lemanov, V.V.; Albers, J.; Klöpperpieper, A. Ultrasonic study of betaine compounds. Ferroelectrics 1998, 208-209, 63-81. [CrossRef]

22. Bauch, J.; Banys, R.; Böttcher, A.; Pöppl, A.; Völkel, G.; Klimm, C.; Klöpperpieper, A. Structural phase transitions in partially deuterated betaine phosphite crystals studied by dielectric and electron paramagnetic resonance methods. Ferroelectrics 1995, 163, 59. [CrossRef] 
23. Balashova, E.V.; Krichevtsov, B.B.; Yurko, E.I.; Svinarev, F.B.; Pankova, G.A. Dielectric Properties of Ferroelectric Betaine Phosphite Crystals with a High Degree of Deuteration. Phys. Solid State 2015, 57, 2382-2388. [CrossRef]

24. Averbuch-Pouchot, M.T. Crystal structure of L-histidinium phosphite and a structure reinvestigation of the monoclinic form of L-histidine. Z. Krist. 1993, 207, 111-120. [CrossRef]

25. Balashova, E.V.; Krichevtsov, B.B.; Popov, S.N.; Brunkov, P.N.; Pankova, G.A.; Zolotarev, A.A. Elastic and Piezoelectric Parameters of the Crystals of Histidine Phosphite L-Hist $\cdot \mathrm{H}_{3} \mathrm{PO}_{3}$ Measured by the Method of Electromechanical Resonance. Tech. Phys. Lett. 2018, 44, 118-122. [CrossRef]

26. Sheldrick, G.M. A short history of SHELX. Acta Cryst. A 2008, 64, 112-122. [CrossRef]

27. Dolomanov, O.V.; Bourhis, L.J.; Gildea, R.J.; Howard, J.A.K.; Puschmann, H. OLEX2: A complete structure solution, refinement and analysis program. J. Appl. Cryst. 2009, 42, 339-341. [CrossRef]

28. Bruker-AXS. APEX2; Version 2014.11-0; Bruker-AXS: Madison, WI, USA, 2014.

29. Sheldrick, G.M. Sadabs; University of Goettingen: Goettingen, Germany, 2007.

30. Momma, K.; Izumi, F. VESTA 3 for three-dimensional visualization of crystal, volumetric and morphology data. J. Appl. Crystallogr. 2011, 44, 1272-1276. [CrossRef]

31. Bruker AXS. TOPAS5 Technical Reference; Brucker AXS: Karlsruhe, Germany, 2014.

32. Thompson, P.; Cox, D.E.; Hastings, J.B. Rietveld refinement of Debye-Scherrer synchrotron X-ray data from $\mathrm{Al}_{2} \mathrm{O}_{3}$. J. Appl. Crystallogr. 1987, 20, 79-83. [CrossRef]

33. Young, R.A. Introduction to the Rietveld Method. In The Rietveld Method; IUCr Book Series Oxford Uni. Press: Oxford, UK, 1993; pp. 1-39.

34. Berger, H. Study of the K alpha emission spectrum of copper. X-ray Spectrom. 1986, 15, 241-243. [CrossRef]

35. Rietveld, H.M. Line profiles of neutron powder-diffraction peaks for structure Refinement. Acta Cryst. 1967, 22, 151-152. [CrossRef]

36. Le Bail, A.; Duroy, H.; Fourquet, J.L. Ab-initio structure determination of $\mathrm{LiSbWO}_{6}$ by X-ray powder diffraction. Mat. Res. Bull. 1988, 23, 447-452. [CrossRef]

37. March, A. Mathematische Theorie der Regelung nach der Korngestalt bei affiner Deformation. Z. Krist. 1932, 81, 285-297.

38. Järvinen, M. Application of symmetrized harmonics expansion to correction of the preferred orientation effect. J. Appl. Cryst. 1993, 26, 525-531. [CrossRef]

39. Bérar, J.-F.; Lelann, P.J. E.s.d.'s and estimated probable error obtained in Rietveld refinements with local correlations. J. Appl. Crystallogr. 1991, 2, 1-5.

40. Levin, A.A.; Filatov, S.K.; Paufler, P.; Bubnova, R.S.; Krzhizhanovskaya, M.; Meyer, D.C. Temperature-dependent evolution of $\mathrm{RbBSi}_{2} \mathrm{O}_{6}$ glass into crystalline Rb-boroleucite according to X-ray diffraction data. Z. Kristallogr. Cryst. Mater. 2013, 228, 259-270. [CrossRef]

41. Walba, H.; Isensee, R.W. Acidity Constants of Some Arylimidazoles and Their Cations. J. Org. Chem. 1961, 26, 2789-2791. [CrossRef]

42. Obodovskaya, A.E.; Starikova, Z.A.; Belous, S.N.; Pokrovskaya, I.E. Crystal and molecular structure of 2-methylbenzimidazole. J. Struct. Chem. 1991, 32, 421-422. [CrossRef]

43. Wächtler, M.; Bräutigam, M.; Poppaband, J.; Dietzek, B. Mechanism of protonation induced changes in Raman spectra of a trisheteroleptic ruthenium complex revealed by DFT calculations. RSC Adv. 2013, 3, 5597-5606. [CrossRef]

44. Güllüoglu, M.T.; Özduran, M.; Kurt, M.; Kalaichelvan, S.; Sundaraganesan, N. Molecular structure and vibrational spectra of 2- and 5-methylbenzimidazole molecules by density functional theory. Spectrochim. Acta Part A 2010, 76, 107-114. [CrossRef]

45. Tsuboi, M. Vibrational Spectra of Phosphite and Hypophosphite Anions, and the Characteristic Frequencies of $\mathrm{PO}_{3}{ }^{2-}$ and $\mathrm{PO}_{2}{ }^{-}$Groups. J. Am. Chem. Soc. 1957, 79, 1351-1354. [CrossRef]

46. Baran, J.; Czapla, Z.; Drozd, M.K.; Ilczyszyn, M.M.; Marchewka, M.; Ratajczak, H. Polarised FTIR and Raman spectra of betainephosphite single crystal I. Paraelectric phase. J. Mol. Struct. 1997, 403, 17-37. [CrossRef]

47. Fleck, M.; Ghazaryan, V.V.; Petrosyan, A.M. Growth and characterization of L-proliniumphosphite. J. Mol. Struct. 2015, 1079, 460-464. [CrossRef]

48. Carey, D.M.; Korenowski, G.M. Measurement of the Raman spectrum of liquid water. J. Chem. Phys. 1998, 108, 7. [CrossRef] 
49. Frost, R.L.; Xi, Y.; Scholz, R.; Belotti, F.M.; Lopez, A. Infrared and Raman spectroscopic characterization of the phosphate mineral fairfieldite- $\mathrm{Ca}_{2}\left(\mathrm{Mn}^{2+}, \mathrm{Fe}^{2+}\right)_{2}\left(\mathrm{PO}_{4}\right)_{2} \bullet 2\left(\mathrm{H}_{2} \mathrm{O}\right)$. Spectrochim. Acta Part A Mol. Biomol. Spectrosc. 2013, 106, 216-223. [CrossRef] [PubMed]

50. Frost, R.L.; Scholz, R.; Belotti, F.M.; Lopez, A.; Theiss, F.L. A vibrational spectroscopic study of the phosphate mineral vantasselite $\mathrm{Al}_{4}\left(\mathrm{PO}_{4}\right)_{3}(\mathrm{OH})_{3} \bullet 9 \mathrm{H}_{2}$ O. Spectrochim. Acta Part A Mol. Biomol. Spectrosc. 2015, 147, 185-192. [CrossRef]

51. Mita, Y.; Takebe, K.; Kobayashi, M.; Endo, S.; Tominaga, Y. Temperature and pressure studies of Raman peaks related to hydrogen modes in KDP. J. Phys. Condens. Matter 2006, 18, 5185. [CrossRef]

52. Litasov, K.D.; Podgornykh, N.M. Raman spectroscopy of various phosphate minerals and occurrence of tuite in the Elga IIE iron meteorite. J. Raman Spectrosc. 2017, 48, 1518-1527. [CrossRef]

53. Lu, G.W.; Sun, X. Raman Study of Lattice Vibration Modes and Growth Mechanism of KDP Single Crystals. Cryst. Res. Technol. 2002, 37, 93-99. [CrossRef]

54. Baran, J.; Ilczyszyn, M.M.; Sledz, M.; Ratajczak, H. Polarised vibrational spectra of $\mathrm{KH}_{2} \mathrm{PO}_{3}$ single crystal. J. Mol. Struct. 2000, 526, 235-254. [CrossRef]

55. Venkateswaran, C.S. The Raman spectra of ortho-phosphoric acid and some phosphates. Proc. Indian Acad. Sci. 1936, 3, 25. [CrossRef]

56. Pawlig, O.; Schellenschlager, V.; Lutz, H.D.; Trettin, R. Vibrational analysis of iron and zinc phosphate conversion coating constituents. Spectrochim. Acta Part A Mol. Biomol. Spectrosc. 2001, 57, 581-590. [CrossRef]

57. Poulet, H.; Mathieu, J.-P. Spectres de Vibration et Syme'trie des Cristaux; Gordon \& Breach: Paris, France, 1970; Chapter 9.

58. Totz, J.; Michel, D.; Banys, J.; Klöpperpieper, A. Conductivity processes in deuterated betaine phosphate (1-x) betaine phosphite (x) mixed crystals. J. Phys. Condens. Matter 1998, 10, 9281-9292. [CrossRef]

59. Balashova, E.V.; Svinarev, F.B.; Ankudinov, A.V.; Pankova, G.A.; Lityagin, G.A.; Kunkel, T.S.; Krichevtsov, B.B. Polarization switching, dielectric, structural and elastic properties of 2-Methylbenzimidazole crystals and films. Ferroelectrics 2019, 538, 74-82. [CrossRef]

60. Jonscher, A.K. Dielectric relaxation in solids. J. Phys. D Appl. Phys. 1999, 32, R57-R70. [CrossRef]

61. Pradhan, D.K.; Choudhary, R.N.P.; Samantaray, B.K. Studies of Dielectric Relaxation and AC Conductivity Behavior of Plasticized Polymer Nanocomposite Electrolytes. Int. J. Electrochem. Sci. 2008, 3, 597-608.

62. Seliger, J.; Žagar, V. Nuclear Quadrupole Resonance Study of Hydrogen Bonds in Solid 2-Methylbenzimidazole and 5,6-Dimethylbenzimidazole. J. Phys. Chem. C 2013, 117, 20193-20200. [CrossRef]

63. Ponomareva, V.G.; Bagryantseva, I.N. Proton Conductivity, Structural and Thermal Properties of (1-x) $\mathrm{CsH}_{2} \mathrm{PO}_{4}-\mathrm{xBa}\left(\mathrm{H}_{2} \mathrm{PO}_{4}\right)^{2}$. Phys. Sol. State 2017, 59, 1829-1835. [CrossRef]

64. Barrett, J.H. Dielectric Constant in Perovskite Type Crystals. Phys. Rev. 1952, 86, 118. [CrossRef]

65. Parker, R.A. Static Dielectric Constant of Rutile $\left(\mathrm{TiO}_{2}\right), 1.6-1060$ K. Phys. Rev. 1961, 124, 1719. [CrossRef]

66. Rowley, S.E.; Hadjimichael, M.; Ali, M.N.; Durmaz, Y.C.; Lashley, J.C.; Cava, R.J.; Scott, J.F. Quantum criticality in a uniaxial organic ferroelectric. J. Phys. Condens. Matter 2015, 27, 395901. [CrossRef] [PubMed] 